\title{
Scaling of columnar joints in basalt
}

\author{
Lucas Goehring ${ }^{1,2}$ and Stephen W. Morris ${ }^{1}$ \\ Received 27 February 2007; revised 17 May 2008; accepted 20 June 2008; published 16 October 2008.
}

[1] We describe field work, analysis, and modeling of columnar joints from the Columbia River Basalt Group. This work is focused on the regions around the Grand Coulee, Snake River, and Columbia Gorge, which form parts of this unusually homogeneous and very large sample of columnar basalt. We examine in detail the scaling relationship between the column width and the size of the striae and relate these quantitatively to thermal and fracture models. We found that the column radius and stria size are proportional to each other and inversely proportional to the cooling rate of the lava. Near a flow margin, our results put observational constraints on diffusive thermal models of joint formation. Deeper than a few meters into a colonnade, our measurements are consistent with a simple advection-diffusion model of two-phase convective cooling within the joints, regardless of the direction of cooling. This model allows an accurate comparison of igneous columnar jointing and joints due to desiccation in laboratory analog systems. We also identify a new length scale in which wavy columns can appear in some colonnades. The mechanisms leading to the wavy columns are likely related to those underlying similar wavy cracks in 2-D analog systems.

Citation: Goehring, L., and S. W. Morris (2008), Scaling of columnar joints in basalt, J. Geophys. Res., 113, B10203, doi:10.1029/2007JB005018.

\section{Introduction}

[2] Columnar jointing has been studied since the Giant's Causeway was first reported to the Royal Society in the 17th century [Bulkeley, 1693]. This formation, in which long vertical prismatic columns cover a shoreline in Northern Ireland, remains one of the most studied and best known outcrops of columnar jointing in the world. It was eventually realized that similar colonnades are common (see, e.g., Figure 1), but their origin was the topic of a longstanding and historically important debate [Tomkeieff, 1940].

[3] The formation of igneous columnar joints is now reasonably understood; the joints result from ordered contraction cracks propagating into cooling lava flows [Mallet, 1875]. As the lava cools and solidifies, the fracture tips follow the solidification front, leaving behind a record of the ordering process in the form of roughly hexagonal columns. The fractures forming the sides of the columns advance in individual, abrupt steps that are recorded by chisel-like markings called striae [Ryan and Sammis, 1978]. The striae can yield a wealth of information about the process of columnar joint formation. Following these insights, work done in the 1980s and 1990s filled in a consistent picture of the cooling dynamics and of the mechanics of the incremental fracture advances [e.g., Ryan and Sammis, 1981; Long and Wood, 1986; DeGraff and Aydin, 1987; Budkewitsch

\footnotetext{
${ }^{1}$ Department of Physics, University of Toronto, Toronto, Ontario, Canada.

${ }^{2}$ Now at BP Institute for Multiphase Flow, University of Cambridge, Cambridge, UK.
}

Copyright 2008 by the American Geophysical Union. 0148-0227/08/2007JB005018\$09.00 and Robin, 1994]. Despite a considerable understanding of how the joints form, at least two significant problems still remain open: the nature of the columnar ordering and the quantitative details of the scaling of the columns.

[4] Columnar joints can be produced in the laboratory using desiccating slurries of starch in water, an effect apparently observed long ago [Huxley, 1881; French, 1925], but which has recently been rediscovered and studied quantitatively [Müller, 1998a, 1998b, 2001]. Furthermore, other studies of the directional propagation of fracture in thin layers has lead to increased understanding of twodimensional analogs of columnar jointing [e.g., Yuse and Sano, 1993; Allain and Limat, 1995; Jagla and Rojo, 2002]. The experience gained from these laboratory analogs suggest possible new interpretations of field data, and may resolve some key questions in igneous columnar jointing.

[5] In this paper, we present detailed observations of columnar jointing from the Columbia River Basalt Group in Washington and Oregon, and compare them to laboratory analogs and thermal models, with the aim of providing quantitative new empirical constraints on the physics of the formation of columnar joints.

\section{Igneous Columnar Jointing}

[6] In lavas, columnar joints form as a result of a cooling front moving from some cooling surface, or flow margin, into the lava, such as from the exposed surface of a lava lake or flood basalt flow [Mallet, 1875]. The rheology of lava is complex, and depends on both temperature, and cooling history. However, while the cooling lava is still above a critical temperature, $T_{g}$, stresses can efficiently be relieved by viscous flow, or plastic deformation [Ryan and Sammis, 


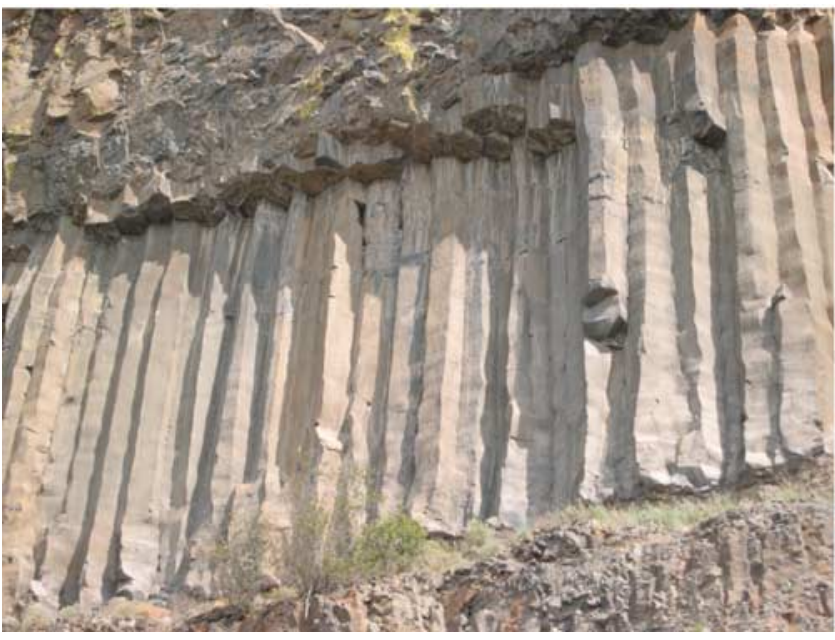

Figure 1. A columnar jointing pattern of a lower colonnade, near Banks Lake, Washington.

1981]. This temperature, known as the glass transition temperature, has been measured directly in Hawaiian lava samples, by observing their stress relaxation behavior over a range of temperatures [Ryan and Sammis, 1981]. Below $T_{g}$, further cooling of the lava leads to an increase in thermal stress, which can no longer be dissipated on a time scale comparable to that imposed by the cooling rate. These thermal stresses are only permitted build up in a thin layer, however, extending over a small temperature range below $T_{g}$. For temperatures too much below $T_{g}$, thermal stresses are instead relieved by either the creation of new cracks, the extension of existing crack tips into the lava, or by the widening of existing cracks. This balance implies that throughout cooling, all the crack tips of the network of columnar joints will be confined to this thin, moving layer, near $T_{g}$ [Ryan and Sammis, 1978]. Observations of the Kilauean lava lakes indicate that surface cracking begins around $900^{\circ} \mathrm{C}$ [Peck and Minakami, 1968]; however, within the bulk of a lava flow, measurements of $T_{g}$ are much lower, approximately $750^{\circ} \mathrm{C}$ [Ryan and Sammis, 1981; Lore et al., 2000].

[7] The columnar crack tips do not extend smoothly with the motion of the intruding stressed layer, but rather advance intermittently, leaving striae on the sides of columns [Ryan and Sammis, 1978]. The striae are typically an alternation of a relatively smooth surface caused by the crack advancing in a brittle medium, and a more rough fracture surface that shows the termination of the crack in a more plastic environment [Ryan and Sammis, 1978]. Subsequent striae are not exactly coplanar, and often the later fracture bends a little to meet the earlier one at right angles (see Figures $2 \mathrm{~b}$ and $2 \mathrm{e}$ ). This slight curvature can be used to infer the direction of crack propagation [DeGraff and Aydin, 1987]. Plumose structure (also known as hackle) appears as a light feathering pattern on the surface of striae (see Figures $2 \mathrm{a}, 2 \mathrm{~d}$, and 2e). These patterns of lines, which form perpendicular to the leading edge of a growing crack tip, can be used to deduce the fracture initiation point of the stria, as well as the direction of propagation [DeGraff and Aydin, 1987]. Unfortunately, these delicate features are easily erased by weathering.

[8] As cooling can occur from both the upper and lower flow margins of a lava flow, typically there are at least two distinct structures in each flow unit [Long and Wood, 1986; DeGraff et al., 1989]. Frequently, these structures are as
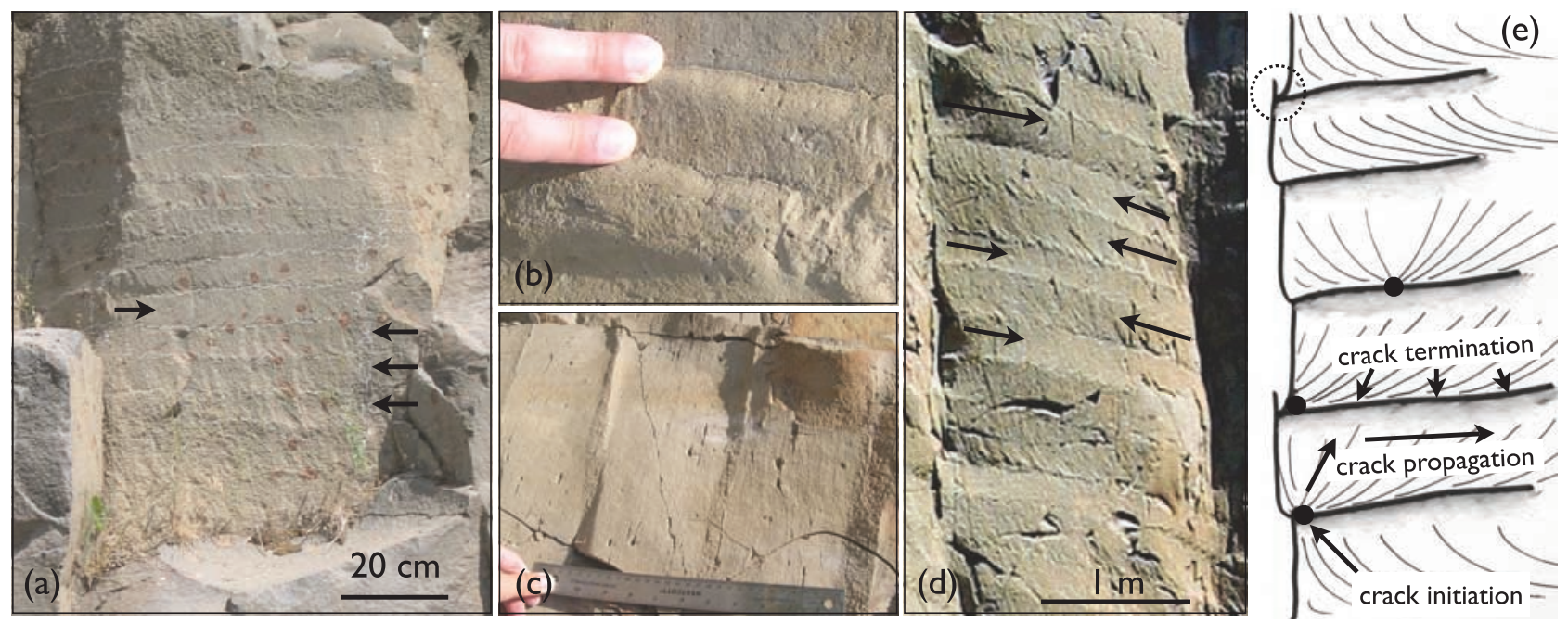

Figure 2. Stria and plumose features. (a) Chalked demarkations of individual striae and some plumose structure. (b) The curvature of several striae that imply that this column cooled from the top of the picture downward. (c) Alternating rough and smooth regions that can be used to measure stria heights. (d) Large striae and plumose. (e) A schematic representation of these features, with the crack initiation points shown as black dots, plumose shown as thin lines, stria edges as thick lines, and the alternation of smooth and rough surfaces as surface shading. A dashed circle in the upper left corner emphasizes that subsequent striae often curve slightly in order to intersect at right angles. Labels indicate the growth stages of a single stria. In Figures $2 \mathrm{a}$ and $2 \mathrm{~d}$, arrows show the inferred direction of crack propagation within individual striae. 
simple as two colonnades: an upper one and a lower one. However, cooling lavas can also support another, less regular, jointing pattern, know as entablature [Tomkeieff, 1940]. This highly disorganized pattern usually has a smaller scale than columnar jointing, and frequently occurs in a band between the upper and lower colonnades (although this is likely simply due to a mismatch of the joints propagating from the separate colonnades). It sometimes partially or entirely replaces the upper colonnade. The mechanisms that distinguish between ordered columnar jointing and disordered entablature are not completely understood, although they have been observed to differ in crystal texture. Entablatures have higher amounts of glassy mesostasis than colonnades from the same flow unit, and contain feathery Fe-Ti oxide crystals [Long and Wood, 1986]. These results imply that the smaller-scale entablature cooled more quickly than the colonnades [Long and Wood, 1986].

[9] The observations of Hardee [1980] on the cooling of an Hawaiian lava lake showed that after an initial period of diffusively dominated cooling, heat was efficiently extracted from the lava through the two-phase convection of water and steam occurring within joints. This idea was developed by Budkewitsch and Robin [1994] and is generally accepted, at least for cooling from the upper surface. For the lower surface, there is no direct evidence yet of this cooling mechanism.

[10] Exposed outcrops of columns exhibit an uncanny degree of regularity and hexagonal order which appears unnatural to the casual observer. In many cases the columns are close to being equal in their cross-sectional areas, and the joints meet at $\mathrm{Y}$ junctions, where the cracks intersect at vertices with three roughly equal $120^{\circ}$ angles. However, the cracks on the surface of a flow containing a colonnade are much less regular, and more like the crack patterns which can be seen in pottery glazes or dried mud [Peck and Minakami, 1968]. They contain a wide distribution of polygon areas, and display mostly $\mathrm{T}$ junctions, where one crack terminates on another crack with a $90^{\circ}$ angle at the vertex. It is remarkable that most of the ordering (the evolution of $\mathrm{T}$ junctions into $\mathrm{Y}$ junctions, and the equalization of column cross-sectional areas) occurs within a meter or two of the flow margin, yet Aydin and DeGraff [1988] have demonstrated just such a process. The forces driving this ordering behavior are still poorly understood. However, the regularity of the interior colonnade is often overstated; even the most well-ordered formations, such as the Giant's Causeway which is many tens of meters thick, still retain a significant number of pentagons and heptagons, and other measurable deviations from a hexagonal ideal [Goehring and Morris, 2005]. Any explanation of the ordering process must also account for this disorder.

[11] The origin of the size, and the overall scaling of columnar joints is also an unresolved issue. Published measurements of stria heights have indicated that they usually vary in direct proportion to the average columnar side width [Ryan and Sammis, 1978; DeGraff and Aydin, 1993; Grossenbacher and McDuffie, 1995]. A number of models have been presented in which the scaling of joints are discussed in light of these suggestive observations [Reiter et al., 1987; DeGraff and Aydin, 1993; Grossenbacher and McDuffie, 1995; Lore et al., 2000; Saliba and Jagla, 2003]. It is generally accepted that larger columns result from more slowly cooled lavas, but there is little consensus on the details of this relationship. New observational insight may help to solve the long-standing problem of fracture spacing in columnar joints.

\section{Experimental Analogs of Jointing in Lava}

[12] Columnar jointing is not unique to igneous rocks, but has also been reported in quenched optical glass [French, 1925], vitrified impure ice [Menger et al., 2002], and desiccating starch slurries [e.g., Müller, 1998a]. A more complete list, including some unusual geological examples, is compiled by DeGraff and Aydin [1987]. In all cases, it is the propagation of a sharp shrinkage front which drives the ordering of contraction cracks. The front can be due to either thermal contraction (as in the case of lava, glass, or vitreous ice) or by shrinkage through desiccation (as in starch slurries).

[13] Several recent studies have focussed on jointing in desiccating starches [Müller, 1998a, 1998b, 2001; Toramaru and Matsumoto, 2004; Goehring and Morris, 2005; Mizuguchi et al., 2005; Goehring et al., 2006]. If allowed to dry freely, a starch slurry will form a colonnade in which the columns slowly increase in scale throughout the drying layer [Müller, 1998a; Goehring and Morris, 2005]. This coarsening is likely due to changes in the shrinkage front, which slows down as it propagates away from the drying surface [Müller, 1998a; Mizuguchi et al., 2005; Goehring et al., 2006]. If the desiccation is controlled in such a way that the shrinkage front propagates at a fixed speed, the coarsening of the colonnade is halted and a scale is selected for the columnar area [Goehring et al., 2006]. Although this scale increases as the drying rate is decreased, there exists a window of stable, propagating columnar scales for any given drying rate [Toramaru and Matsumoto, 2004; Goehring and Morris, 2005; Goehring et al., 2006]. The pattern that develops in desiccated starch has been shown to be statistically similar to that of the Giant's Causeway [Goehring and Morris, 2005], but does not evolve to a perfect hexagonal arrangement. Instead, there appears to be a well-defined amount of disorder inherent in the "mature" columnar pattern. For example, the density of penta-hepta defects in the pattern of columnar jointing is the same whether one looks at the Giant's Causeway, or starch columns in cross section [Goehring and Morris, 2005]. In starch, the details of this pattern do not depend on the drying rate, or the scale of the columns.

[14] Directional fracture patterns in thin sheets may be regarded as the two-dimensional analogs of columnar joints. Systems of cracks with regular spacing have been studied in several different experimental contexts. Dipping a thin heated strip of glass or silicon into cold water results in fractures due to thermal stresses [Yuse and Sano, 1993; Ronsin and Perrin, 1987]. Similar patterns emerge in fractures due to the directional drying of a thin layer of a granular or colloidal suspension [Allain and Limat, 1995; Shorlin et al., 2000; Dufresne et al., 2003]. In general, the average fracture spacing depends on the thickness of the drying layer. However, as with desiccated starch, hysteresis is important in setting the crack spacing for given conditions [Shorlin et al., 2000; Deegan et al., 2003]. In some cases, 


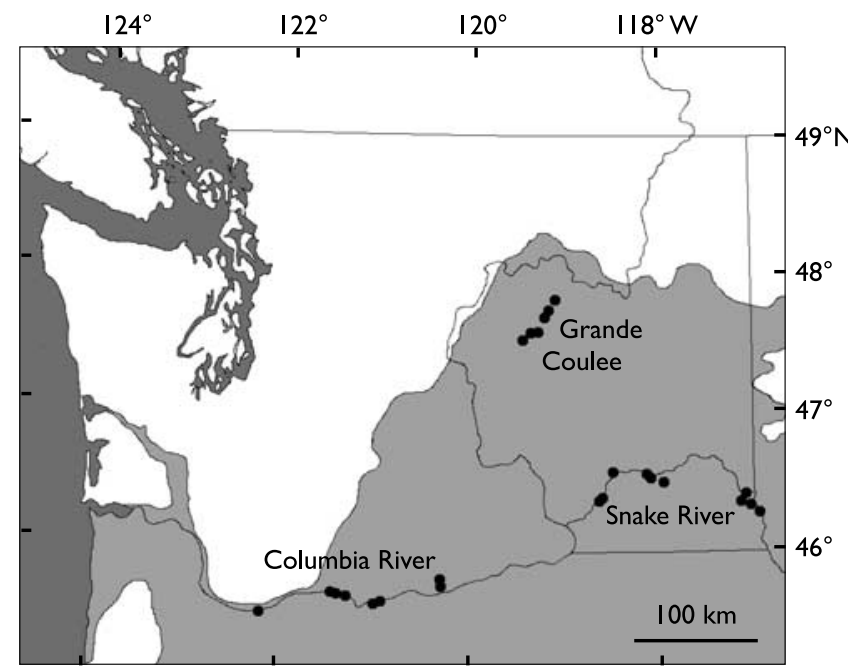

Figure 3. Location of field sites (black circles) and the Columbia River Basalt Group (shaded region, adapted from Hooper and Kawkesworth [1993]), in and around Washington state. Some sites are close enough to each other to overlap at this scale.

fractures advance with an intermittent motion similar to the behavior that produces striae in columnar joints [Dufresne et al., 2003, 2006], although this is not observed in all materials.

[15] One important aspect of fracture in a thin heated strip is the presence of a secondary, oscillatory instability. When the crack front is moving quickly enough, or the crack spacing is large, individual cracks can propagate in a wavelike, or undulatory way [Yuse and Sano, 1993]. In section 8.4, we show that a similar and previously unreported undulatory instability is also present in some igneous colonnades.

\section{Columbia River Basalt Group}

[16] We chose the Columbia River Basalt Group (CRBG) as an ideal site for field studies of columnar jointing. Recent geological and human activities have exposed fresh basalt surfaces. The current dry climate of the region has helped to preserve delicate striae and plumose structures on the column faces. The homogeneity and extent of the CRBG allows access to a large number of study sites that are compositionally identical. Differences in jointing between sites, therefore, can be primarily attributed to differences in cooling dynamics, and not to differences in material properties.

[17] The CRBG is a large igneous province that formed when the Yellowstone hot spot impinged on the continental crust around 17.5 Ma [Hooper and Kawkesworth, 1993; Coffin and Eldholm, 1994]. Several hundred massive basalt flows were released over approximately the next $10 \mathrm{Ma}$, which covered a significant part of Washington and Oregon states over a kilometer deep in lava. The majority $(>85 \%)$ of activity was confined to the Grande Ronde Basalt Formation (16.5-15.6 Ma), whose feeder dikes lie near the Washington-Oregon-Idaho border [Tolan et al., 1989]. These flows are compositionally very similar, typically $\sim 54 \% \mathrm{SiO}_{2}$, and are classified as low-Al tholeiitic basalt
[Hooper and Kawkesworth, 1993; Reidel et al., 1989]. Studies of crystal texture and chemical differentiation imply that the flow was laid down through laminar flow and inflation beneath an insulating, solidified, crust [Shaw and Swanson, 1970; Ho and Cashman, 1997; Thordarson and Self, 1998]. This, in turn, implies that not only was the source lava relatively homogeneous in time, but that it produced undifferentiated, isothermal lava flows across the Columbia Plateau. Emplacement temperatures are tightly constrained by these data, and are estimated to be 1085$1095^{\circ} \mathrm{C}$ in the Ginko flow of the CRBG [Ho and Cashman, 1997]. Owing to the presence of the insulating crust, the variation in the initial temperature of the bulk of these lavas likely varied by less than $0.1^{\circ} \mathrm{C}$ per kilometer from the dike swarms that generated them [Thordarson and Self, 1998].

[18] Long and Wood [1986] have categorized three flow types that are common in the CRBG. The flow types are end-members of a continuum of flow characteristics that can be found in the Columbia Plateau, and do not necessarily imply genetic differences between flows types. However, Thordarson and Self [1998] have shown that emplacement by large pahoehoe sheet lobes of the Roza Member tended to result in type I flows, $10-30 \mathrm{~m}$ thick, which have large $(>1 \mathrm{~m})$ irregular, tapering columns. These flows were often laid down on a dry substrate, composed of volcanic products from the same eruption [Thordarson and Self, 1998]. Alternatively, type II and III flows are typically thicker (30$80 \mathrm{~m}$ thick), with well-formed colonnades, and more likely to contain thick entablature layers than type I flows. Type III flows contain a single upper colonnade or entablature, while type II flows contain more than one well-defined upper tier structure. It is thought that in these thicker flows, the percolation of water through joints has influenced their cooling [Long and Wood, 1986].

[19] Recently, during the last ice age, the scablands of the Columbia Plateau were created through a series of catastrophic floods, caused by the periodic breakdown of an ice dam on glacial Lake Missoula [Bretz et al., 1956; Waitt, 1985]. These floods, along with the action of the Columbia and Snake rivers, have produced a series of accessible and relatively recently exposed flow units.

\section{Observational Methods}

[20] We studied 27 sites in three areas (the Grand Coulee between Electric City and Soap Lake, the Snake River from near Clarkston to the Tri-Cities, and the Columbia River between Portland and Rock River Road) as shown in Figure 3. Our study thus covered a wide range of the Grande Ronde and Wanapum basaltic units of the CRBG, but did not extend beyond these formations. The flows we studied can typically be grouped with the type II or type III flows. Information on the structure of these field sites is included in the auxiliary material. ${ }^{1}$

[21] At each field site, we measured a number of geometric features of one particular colonnade. We attempted to make at least 20 measurements of each variable studied, in order to obtain reasonable statistics for the mean and standard deviation. When possible, we measured the widths

${ }^{1}$ Auxiliary materials are available in the HTML. doi:10.1029/ 2007JB005018. 


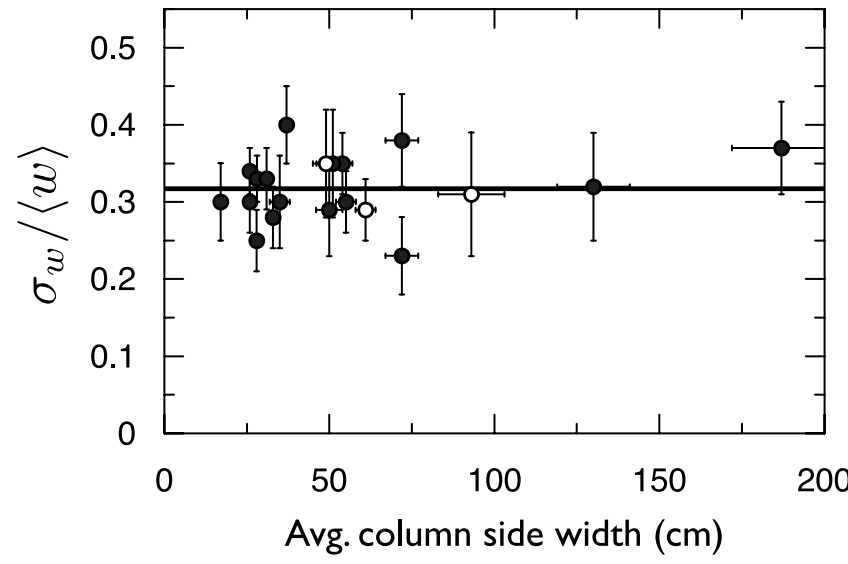

Figure 4. A relative measure of the disorder in the column sizes for 20 sites in the CRBG. We plot the standard deviation divided by the mean of the column edge width distribution, a dimensionless ratio that would be zero for perfect hexagonal columns. There is no dependence of the value of this parameter on either column size or cooling direction. The 17 sites indicted by black circles are lower colonnades, or sites with an uncertain direction of cooling, while those 3 sites indicated by white circles represent upper colonnades. The solid line is an error-weighted mean. The value of this mean is identical, within error, to the value observed in the pattern of columnar jointing in desiccated starches [Goehring and Morris, 2005].

of column faces, the angle between joints meeting at a vertex, the heights of individual striae, and the position of the upper and lower flow surfaces, and inferred the direction of cooling from stria features. The measurements made at any site were determined both by accessibility, and by erosion or other damage to the colonnades, which usually limited data collection to only two or three of these types of observables. Further information on the distribution of measurements at the field sites can be found in the auxiliary materials.

[22] We found that lower colonnades, those that cooled from the base up, represented 15 of the 18 distinct colonnades included in this study on which we could make a conclusive determination of the direction of crack propagation. This should not be taken to imply anything about the relative frequency of upper versus lower colonnades, however. Although basalt is a hard, weather-resistant rock, which does not erode easily, the columns themselves can be easily dislodged. Indeed, most colonnades have copious columnar rubble at their base. This mode of erosion usually means that the regions near the lower surface of a flow unit are much more accessible than the upper limits of that same flow.

[23] Column faces widths $w$ were measured to $\pm 1 \mathrm{~cm}$, which reflects the difficulty of measuring a dimension that is often not completely constant over a column's height. All but one site had a set of column widths measured, although in six additional cases the studied colonnade was sufficiently damaged to yield less than ten reliable column width measurements.

[24] Three measurements were usually made of the height, $s$, of each stria (at the middle, and near either edge of the column face), each measurement accurate to $\pm 0.25 \mathrm{~cm}$.
As the stria height can vary (typically by 0.5 to $1 \mathrm{~cm}$ ) across the face of a column, this minimizes our measurement error. When the slight curvature of striae has not been eroded, subsequent striae can sometimes be seen to overlap by a few millimeters (see Figures $2 \mathrm{~b}$ and $2 \mathrm{e}$ ). In these cases, to avoid counting the same height twice, we measured stria height from the initiation point of each stria to the point where it intersected with the subsequent stria. Over twelve hundred striae were measured in total, summing across 20 different sites. At four of these sites, where the state of preservation was exceptional, it was possible to measure stria heights to $\pm 0.1 \mathrm{~cm}$ precision. In six cases, where striae were observed near a flow margin, the distance between the flow margin and the start of the recorded sequence of striae was measured for each column. The lava flow margins were often slightly irregular, which presented measurement difficulties, and we therefore estimate an error of between 10 and $25 \mathrm{~cm}$ in such measurements. The direction of cooling was determined by observations of plumose structure and striae, as described by DeGraff and Aydin [1987] and shown in Figure 2.

[25] The vertex angles $\theta$ of columnar joints were measured with an estimated error of $\pm 5^{\circ}$, in five cases where erosion had not rounded off the column edges. It was difficult to make accurate measurements of joint angles on standing columns because of the constrained geometry. Instead, most joint angle data were taken from nearby columnar rubble.

[26] In this paper, $\langle x\rangle$ will denote the average of a set of measurements of quality $x$, while the standard deviation at that site is represented by $\sigma_{x}$. Error bars and ranges provided are equal to the standard error on a measurement.

\section{Observations}

[27] This section will present graphical and statistical descriptions of our observations on columnar joints in the Columbia River Basalt Group. The original data sets which support this section are published as auxiliary materials. These materials include stratigraphic descriptions, GPS coordinates, and accessibility information for each field site, as well as records of all individual measurements made during the course of our study.

\subsection{Columnar Ordering}

[28] It has long been known that the pattern of columnar jointing contains some disorder. We have recently quantified this statement by reporting that 'mature' patterns of columnar joints in corn starch retain a certain, highly repeatable, level of disorder [Goehring and Morris, 2005]. In dried starch colonnades, more than one $\mathrm{cm}$ away from a drying surface, the details of the relative distribution of column sizes, edge widths, and number of neighbors, and of joint angles, are constants that do not depend on the size of columns, or on the methods used during drying [Goehring and Morris, 2005]. It is insightful to compare the degree of disorder found in that system to that which we have observed in lava.

[29] We measured the statistics of face widths $w$ at a range of sites in different flow units. Figure 4 shows a representative dimensionless statistic for the degree of disorder in the column width distribution for the 20 sites where at least 
Table 1. Statistical Measures of Disorder in Columnar Jointing ${ }^{\mathrm{a}}$

\begin{tabular}{cccccc}
\hline \multicolumn{1}{c}{ Description } & $\sigma_{A} /\langle A\rangle$ & $\sigma_{w} /\langle w\rangle$ & $\sigma_{N}$ & $\sigma_{\theta}$ & Percent $105^{\circ}-135^{\circ}$ \\
\hline Dessicated starch $^{\mathrm{b}}$ & $0.32 \pm 0.01$ & $0.313 \pm 0.015$ & $0.86 \pm 0.05$ & $14.6 \pm 0.3^{\circ}$ & $70.1 \pm 1.7 \%$ \\
Giant's Causeway $^{\mathrm{c}}$ & $0.32 \pm 0.02$ & $0.342 \pm 0.02$ & $0.75 \pm 0.06$ & $14.3 \pm 0.6^{\circ}$ & $69.7 \pm 1.4 \%$ \\
CRBG & - & $0.317 \pm 0.009$ & - & $15.6 \pm 1.2^{\circ}$ & $67 \pm 3 \%$ \\
\hline
\end{tabular}

${ }^{\text {a } T h e ~ r e l a t i v e ~ v a r i a t i o n ~(s t a n d a r d ~ d e v i a t i o n ~ d i v i d e d ~ b y ~ t h e ~ m e a n) ~ i n ~ c o l u m n ~ c r o s s-s e c t i o n a l ~ a r e a ~} A$; relative variation in edge width $w$; standard deviation in the number of neighbors $N$; standard deviation in the joint angle $\theta$; the fraction of Y junctions.

${ }^{\mathrm{b}}$ Goehring and Morris [2005].

${ }^{\mathrm{c}}$ Calculated from data of O'Reilly [1879].

ten measurements were made. This relative variation (the standard deviation divided by the mean) of the distribution of column sizes is remarkably consistent, even for widely separated sites in the CRBG. In particular, there is no dependence of the relative variation of the column edge width distribution on the size of the colonnade; a best fit value of $\sigma_{w} /\langle w\rangle=0.317 \pm 0.009$ has a chi-square value of 14.6, with 19 degrees of freedom, indicating a strong confidence in this result. As shown in Table 1, this value agrees within error with the value of $\sigma_{w} /\langle w\rangle$ found in columnar corn starch. We find this agreement to be remarkable, as it implies that the disorder of the columnar pattern does not significantly depend on small-scale inhomogeneities in crystal texture, glass concentration, or vesicularity.

[30] We also measured the distribution of the joint angles $\theta$ at five sites. The distribution of joint angles was similar at all sites, and, as expected, was clustered around $120^{\circ}$. Our results for various statistics diagnostic of disorder in the CRBG are displayed in Table 1, along with statistics of columns in desiccated corn starch, and those derived from the O'Reilly [1879] survey of the Giant's Causeway. Again, all show essentially identical levels of inherent residual disorder.

\subsection{Stria Height Versus Column Width}

[31] To investigate the scaling features of columnar jointing, we measured stria features and column side widths at 18 different sites. The average height of striae varied from $36 \mathrm{~cm}$ near the Dalles Dam (see Figure 2d), to only $3.6 \mathrm{~cm}$ near Clarkston. Our observations of striae indicate that they tend to scale in direct proportion to the size of the column face width. Across all our sites we find that the ratio of the average stria height $\langle s\rangle$, to the average column width $\langle w\rangle$, $\eta=\langle s\rangle /\langle w\rangle$, has a mean value of $0.14 \pm 0.02$, with a standard deviation of $0.06 \pm 0.02$. The correlation coefficient of this linear regression is high, 0.9 , as shown in the averaged data presented in Figure 5a. Although there are some fluctuations, the statistics agree well with those of DeGraff and Aydin [1993], who collected data across eight sites throughout the Western United States, and with Grossenbacher and McDuffie [1995], who suggested that the range of $\eta$ was between 0.05 and 0.2. All of our averaged stria height measurements are within this range. When striae are considered individually, however, it becomes apparent that there are several sites which display a very wide scatter in stria heights. Other sites show a very tight distribution of stria heights. These data are shown in Figure 5b. The scatter apparent here has two sources: an increase in stria height as one moves away from the flow margin and a random variation of individual stria heights. The spread of the data also suggests that there may be no uniquely defined relationship between $s$ and $w$ but rather that there might exist a narrow range of allowed ratios $\eta$ which are stable under the evolution of the fracture network.

\subsection{Stria Heights Versus Position Relative to the Flow Margin}

[32] At six sites, conditions were favorable to measure the spatial distribution of stria heights, as shown in Figure 6. At three of these locations, shown in Figures $6 a-6 c$, measurements were made near the basal flow margin. In a fourth
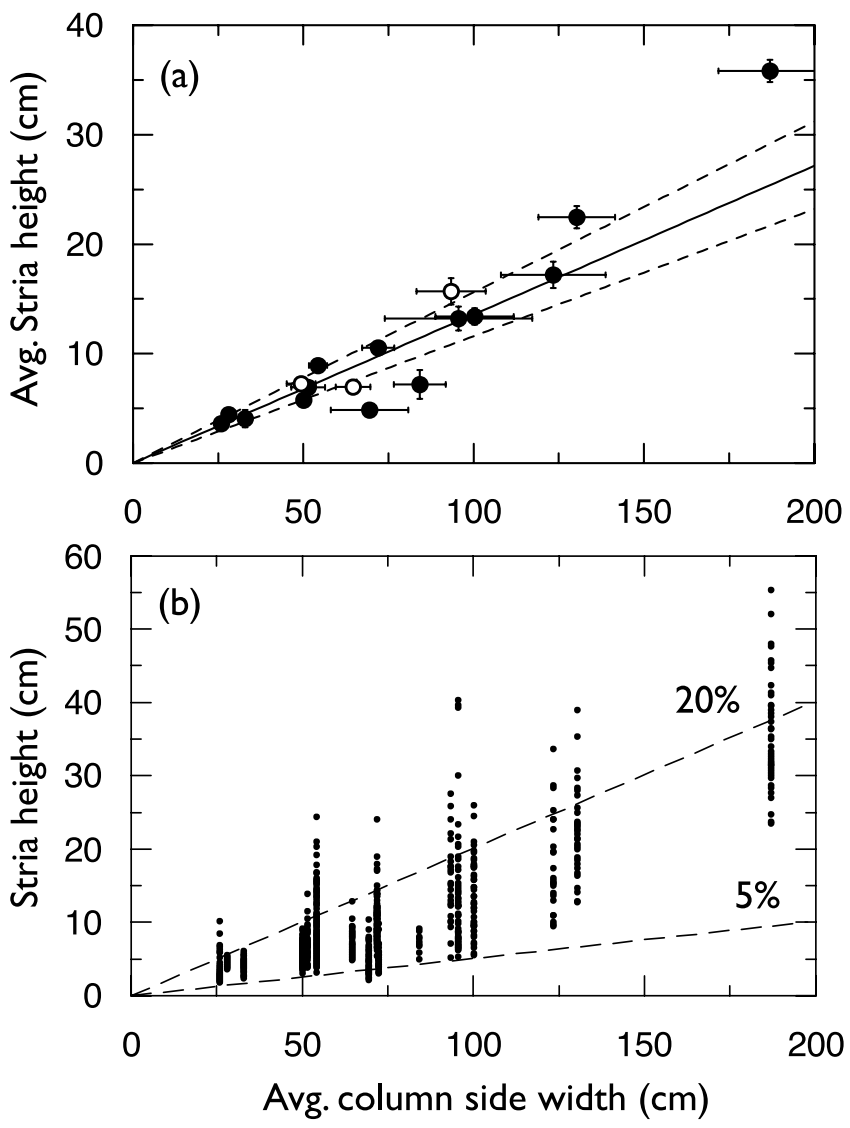

Figure 5. The distribution of stria heights and column widths. (a) The average stria height $\langle s\rangle$ and column edge width $\langle w\rangle$ at each site. (b) The unaveraged stria measurements at each site (errors are $\pm 0.25 \mathrm{~cm}$ on each measurement). In Figure 5a, black circles represent lower colonnades, while white circles represent upper colonnades. A solid line shows the best fit ratio $\eta=\langle s\rangle /\langle w\rangle=0.14$, while dashed lines show the \pm 0.02 error range on $\eta$. In Figure $5 b$, for comparative purposes, the dashed lines show $\eta=0.05$ and 0.2 , the bounds suggested by Grossenbacher and McDuffie [1995]. 

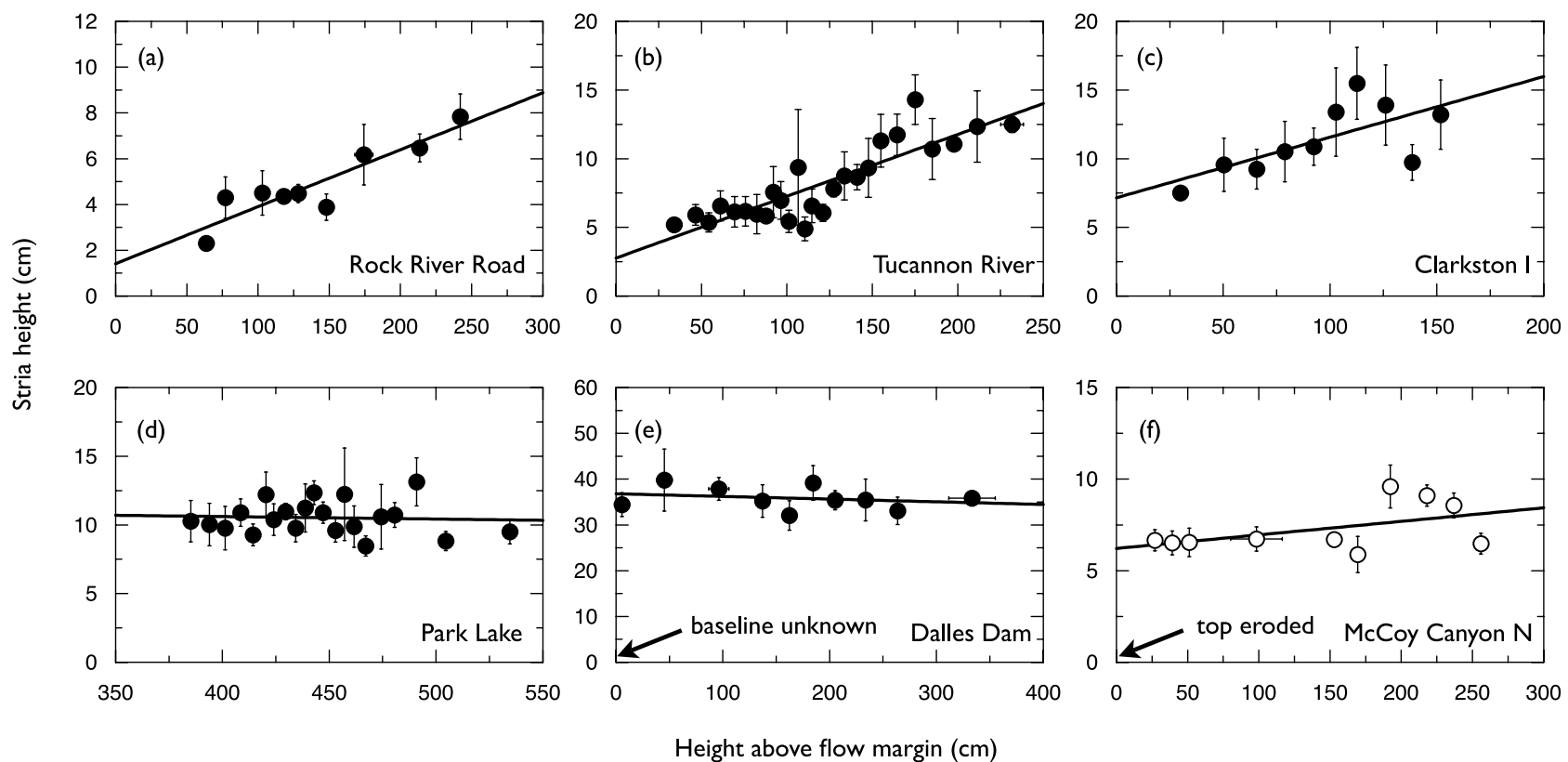

Figure 6. Variations in stria height as a function of distance from flow margins. The data shown are averaged over groups of five striae, with best fit lines drawn to indicate the dependence of the stria height on distance from the flow margin. In Figures $6 a-6 \mathrm{c}$ the fits give slopes of $2.5 \pm 0.5 \%, 4.5 \pm 0.6 \%$, and $3.2 \pm 1.3 \%$, respectively, with correlation coefficients of $0.9,0.9$, and 0.7 . These results show conditions in which the average stria height depends on position. Similar linear regressions in Figures $6 \mathrm{~d}-6 \mathrm{e}$, which show data further away from the flow margin, yield slopes of $-0.2 \pm 0.7 \%$, and $-0.6 \pm 1 \%$, respectively, with correlation coefficients of 0.06 and 0.08 . In these data sets, there is no significant dependence of stria height on position. Figure $6 \mathrm{f}$ shows data from an upper colonnade, where the distance to the upper flow margin is unknown. The striae may be increasing slightly, as a linear regression yields a slope of 0.7 $\pm 0.3 \%$, with a correlation coefficient of 0.3 .

location, shown in Figure 6d, a convenient scree pile allowed us to accurately estimate the distance from the measurements to the base of the flow. In the fifth case, shown in Figure 6e, we could not accurately determine the distance above the base of the flow, although observations of the surroundings implied that measurements were made at least several meters above the flow margin. The final location, shown in Figure 6f, was the only case where we observed the stria distribution with respect to vertical position in an upper colonnade. In this colonnade, unfortunately, erosion prevented any reliable estimate of the position of the top of the flow unit.

[33] The data in Figures $6 a-6 c$ suggest that near a flow margin, the average stria height in a lower colonnade increases linearly with the distance away from the flow margin. In contrast, the data in Figure $6 \mathrm{~d}$ present an example where all striae between 375 and $550 \mathrm{~cm}$ away from the flow margin are randomly distributed around an average, while Figure 6e shows a similar situation extending over several meters of colonnade thickness. In general, sufficiently far from the basal flow margin, the stria height stops increasing and we observed no significant trend in the spacing of stria with position. This lack of a trend can also be seen in Figures $7 \mathrm{a}-7 \mathrm{c}$, which shows the relative height of the $n$th stria, $s_{n} /\langle s\rangle$, plotted against the relative height of the subsequent stria, $s_{n+1} /\langle s\rangle$. Several cases of apparent correlation, such as that shown in Figure $7 d$, can all be interpreted as arising from changes in the average stria height near a flow margin. Interestingly, in no case was an anticorrelation between consecutive stria heights observed. Such an anticorrelation might have been expected if a larger than average crack advance was in some way compensated for by a shorter advance of the subsequent stria. On the contrary, no such interaction between successive striae was observed.

\subsection{Statistical Distribution of Stria Heights}

[34] The data presented in Figure 7e show that the ratios of adjacent stria heights, from different sites, all have a similar distribution of values, including observations from both the upper and lower colonnades, and from striae near to and far away from a flow margin. The one exception to this rule, at the Devil's Canyon, has a somewhat tighter distribution of stria heights. In general, the data suggest that each stria advance is well described as a statistically independent event. If this is the case, then it follows from basic statistical theory that the standard deviations of the probability distribution functions for $s_{n} /\langle s\rangle$ and $\left(s_{n}-s_{n+1}\right) /\langle s\rangle$ should differ by a factor of $\sqrt{2} \approx 1.4$. Here $s_{n}$ and $s_{n+1}$ are two subsequent striae, as defined by the direction of cooling, on any column. We found these standard deviations to be $21 \pm 1 \%$ and $31 \pm 1 \%$, and hence their ratio is $1.45 \pm$ 0.08 , which is in agreement with the expectation for independent events.

[35] The covariance between $s_{n}$ and $s_{n+1}$ can also be used as a test of their statistical independence, where the covari- 

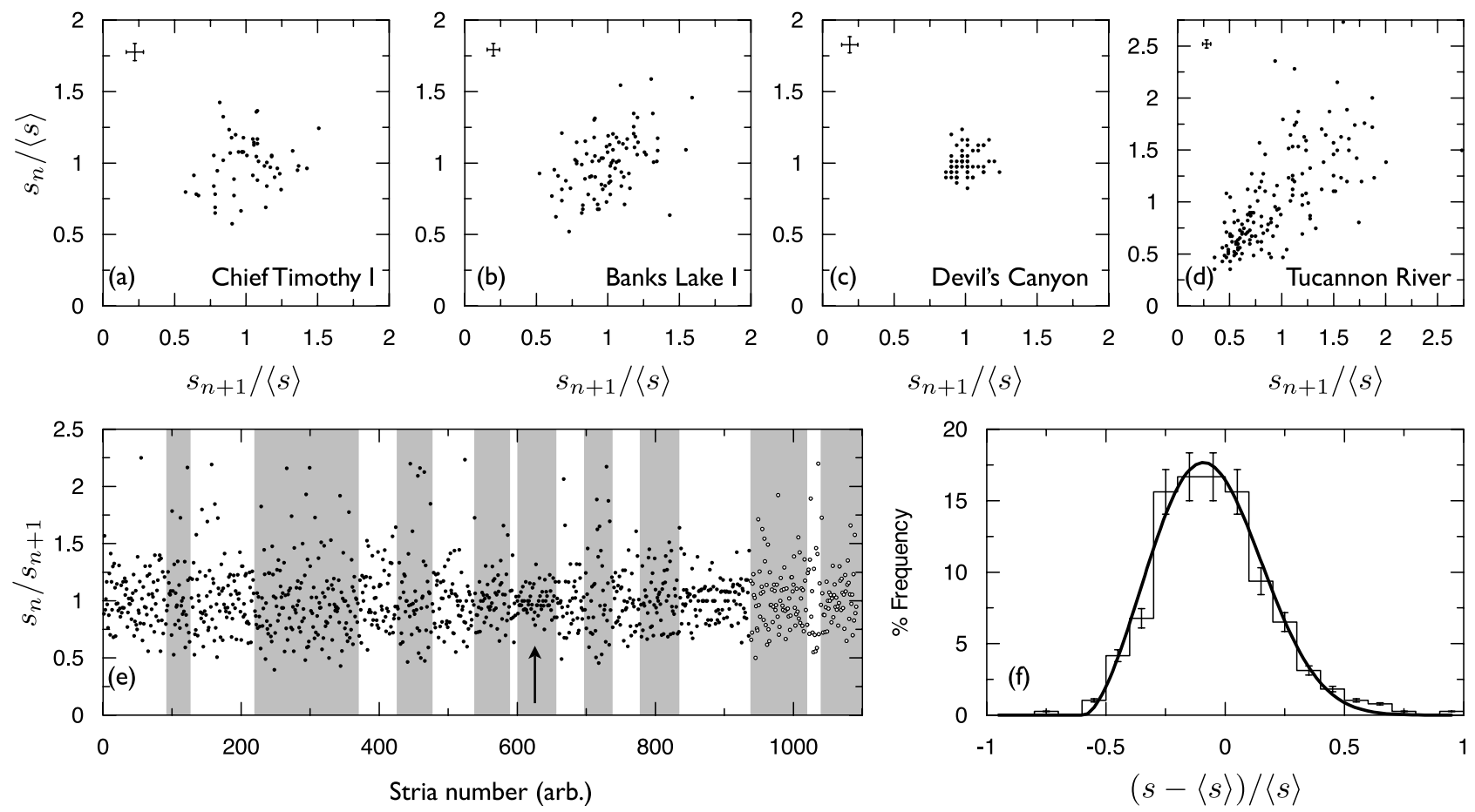

Figure 7. A statistical analysis of the correlations between subsequent stria heights. In Figures $7 \mathrm{a}-7 \mathrm{~d}$, the relative height of each stria, $\mathrm{s}_{n} /\langle s\rangle$, is plotted against the relative height of the subsequent stria, $\mathrm{s}_{n+1} /$ $\langle s\rangle$. Error bars displayed in the upper left of Figures $7 \mathrm{a}-7 \mathrm{~d}$ show the typical observational error of $\pm 2.5 \mathrm{~mm}$. Figures $7 \mathrm{a}$ and $7 \mathrm{~b}$ show typical of most data sets. Site in Figure $7 \mathrm{c}$ is singularly unusual in our data, in that successive stria heights are much more constant than any other site. The correlation apparent in Figure $7 \mathrm{~d}$ is due to a gradual increase in stria height as a function of position away from a flow margin. Figure $7 \mathrm{e}$ shows that the ratio $\mathrm{s}_{n} / \mathrm{s}_{n+1}$ is not dependent on the site, or on the position in the flow. Alternations between white and grey backgrounds distinguish between data from different sites. The arrow points to the exceptionally constant Devil's Canyon data. White circles show data from upper colonnades, while dark circles show data from lower colonnades. Figure $7 \mathrm{f}$ shows that the probability distribution function of the stria height is well described by a Weibull distribution.

ance $\operatorname{Cov}\left(s_{n}, s_{n+1}\right)=\left\langle s_{n} s_{n+1}\right\rangle-\left\langle s_{n}\right\rangle\left\langle s_{n+1}\right\rangle$. If $s_{n}$ and $s_{n+1}$ are statistically independent random variables, then it is a basic statistical result that $\operatorname{Cov}\left(s_{n}, s_{n+1}\right)=0$. We calculated this covariance for data from eight sites where at least 20 sequential measurements of striae were made and where there was no obvious correlation between $s_{n}$ and $s_{n+1}$ due to the proximity to a flow margin. Explicit results are included in the auxiliary materials; in all cases the calculated covariance is consistent with zero.

[36] The distribution of individual stria heights is presented in Figure 7f. Only data obtained well away from a flow margin was used to prepare this distribution. A fit of a gaussian distribution to this data is suggestive, but cannot explain either the asymmetry of the data around the mean, or the slower-than-exponential decrease in the tails of the distribution. A Weibull probability distribution function,

$$
p_{w}(s)=\frac{k}{b}\left(\frac{s-s_{0}}{b}\right)^{k-1} e^{-\left(\left(s-s_{0}\right) / b\right)^{k}},
$$

better captures both these unusual features of the data and is commonly used to model failure or fracture phenomena [Weibull, 1951]. A best fit of the shape parameter $k=2.7 \pm$ 0.2 , the scale parameter $b=0.56 \pm 0.03$, and an offset $s_{0}=$
$-0.51 \pm 0.03$ in equation (1) to the probability distribution of the relative stria heights is shown in Figure $7 \mathrm{f}$. This type of distribution would naturally arise in a material where the local tensile strength at the crack tip is a random variable with a fixed variance, and where a fracture, once active, runs until the tip reaches some lower, fixed, termination stress. Weibull statistics would follow from the observation that fracture can initiate at any position along the column edge (although the vertices are preferred initiation sites), and that failure of the weakest point causes the failure of the entire crack edge. This distribution could also arise if crack advances are coupled in some way, if the arrival of a crack advance at a vertex triggers crack advances on other edges sharing that vertex, for example.

[37] Although the cross-sectional areas of columnar joints are often remarkably uniform within the bulk of a colonnade, it has been shown that in many cases, within about $1-$ $3 \mathrm{~m}$ of a flow margin, the column size can coarsen somewhat [Peck and Minakami, 1968; DeGraff and Aydin, 1993; Lore et al., 2000]. Furthermore, analog experiments in corn starch have shown that this coarsening, a gradual increase in the average column diameter with respect to vertical position, is likely the result of a deceleration of the solidification front as it penetrates into the flow [Goehring 

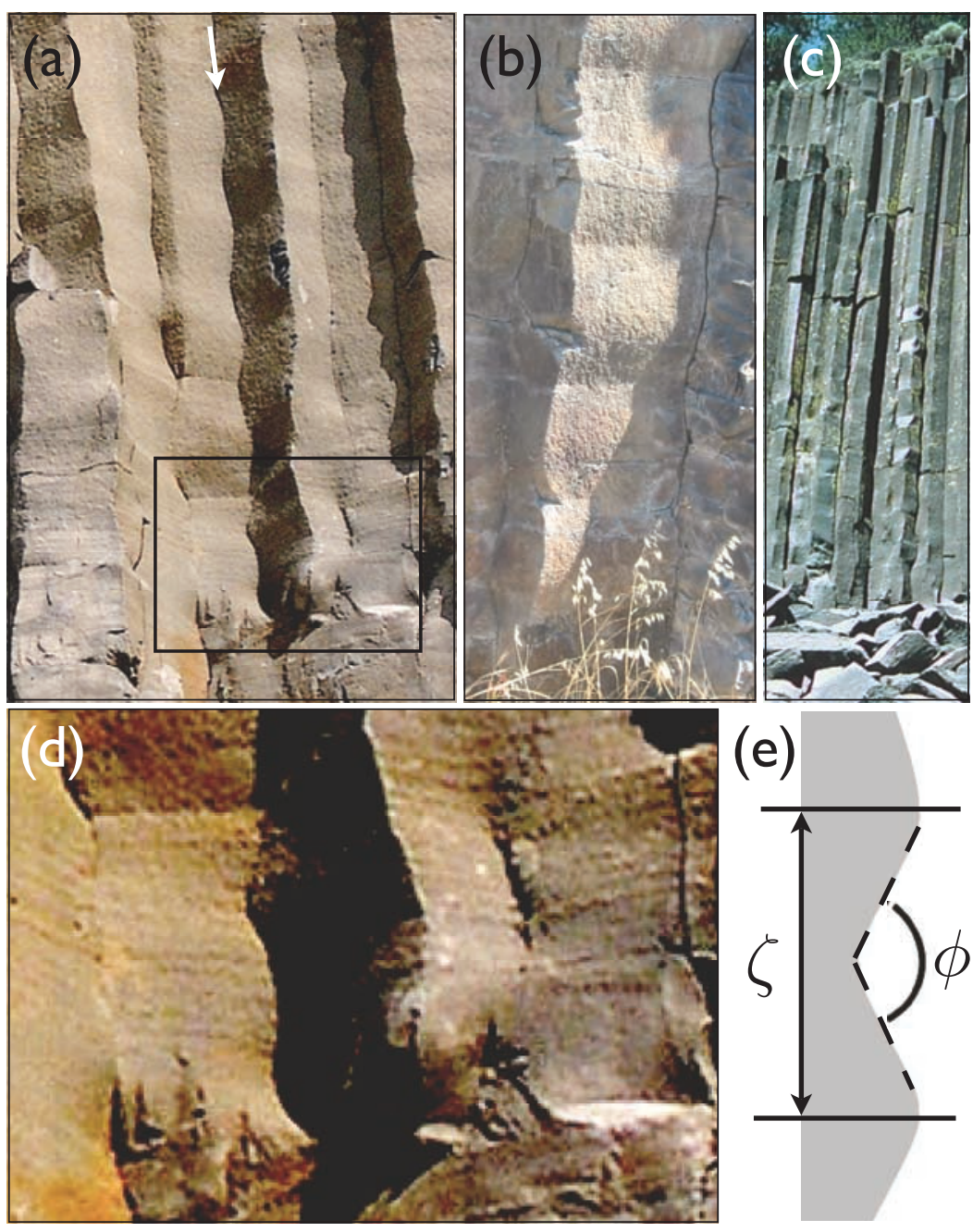

Figure 8. Examples of wavy columns from the (a) Banks Lake II, and (b) Bingen II sites. This undulation of the column faces can also be observed at (c) the Devil's Postpile, in California. In Figure 8a, the inner joint between two wavy columns, marked by an arrow, can be seen to undulate. This indicates that wavy columns are not an erosional pattern. (d) The region indicated by a rectangle in Figure 8a is shown close up, with enhanced contrast in order that the striae can be seen. The wavelength of the undulations is much larger than the width of the striae. (e) A sketch of the surface of a wavy column, as it would appear in cross section (cut perpendicular to the column surface, and parallel to the direction of crack propagation) and how the wavelength $\zeta$ and angle $\phi$ of wavy columns are defined.

et al., 2006]. These analog experiments showed that coarsening is halted when a steady state front velocity is reached. Thus, in the types of flows we observed, the column size and the stria height both evolve near the flow margin, but reach statistically stable average values more a few meters away from it. This may be contrasted with the more irregular colonnades sometimes present in type I flows, which have been described as coarsening throughout their thickness [Long and Wood, 1986].

\subsection{Undulations of the Column Width}

[38] The column size and stria height are not the only length scales exhibited by columnar joints. During our field work, we discovered an additional length scale inherent to columnar jointing, the scale associated with a periodic undulation of the column faces. This undulation takes the form of alternating regions where the cracks defining individual column faces advance and retire slightly, in the direction that would be otherwise normal to the column surface. This gives rise to a regular oscillation of the faces of columns, as shown in Figure 8. These "wavy columns" are uncommon, and only occurred at a small number of the sites visited. The half wavelength of the undulations is significantly larger than the stria height (see Table 2), and so the undulations must be the result of collective behavior occurring over several crack advances. On the other hand, the full wavelength, $\zeta$, of the undulations (see Figure 8e) is approximately equal to the column edge width, or the column radius. It is unclear if these undulations have sharp peaks, which have subsequently been smoothed by weathering, or if they form as smooth, roughly sinusoidally curving surfaces. In either case, much of a wavy column's surface consists of almost flat faces, alternating slightly to one side, then the other, of the average direction of 
Table 2. Column Face Width ${ }^{\mathrm{a}}$

\begin{tabular}{lcccc}
\hline Site Description & $\langle s\rangle(\mathrm{cm})$ & $\langle w\rangle(\mathrm{cm})$ & $\langle\zeta\rangle(\mathrm{cm})$ & $\langle\phi\rangle$ \\
\hline Chief Timothy & $4 \pm 0.2$ & $32 \pm 2$ & $44 \pm 3$ & $164 \pm 2^{\circ}$ \\
Rock Creek & - & $17 \pm 2$ & $16 \pm 2$ & $163 \pm 2^{\circ}$ \\
Shepherd's Dell & - & $35 \pm 3$ & $36 \pm 4$ & $158 \pm 2^{\circ}$ \\
Bingen II & - & $31 \pm 2$ & $39 \pm 2$ & $164 \pm 2^{\circ}$ \\
Banks Lake II & $6 \pm 1$ & $55 \pm 3$ & $68 \pm 10$ & - \\
\hline
\end{tabular}

${ }^{a}$ The parameter $\zeta$ is the crest separation of each undulation (i.e., its full wavelength), and $\phi$ is the angle defined by the intersection of planes tangent to the flat faces of the column on either side of a crest. The oscillation wavelength is approximately equal to width of the column face.

propagation of the column face. We can define a kink angle, $\phi$, between these subsequent near-planar regions, as is shown in Figure 8e. This kink angle was observed to be reasonably constant at about $160^{\circ}$ at all sites where undulations were observed, as shown in Table 2. Assuming the undulations have a single scalable shape, this result would imply that the amplitude of the undulations scales linearly with the column diameter.

[39] Wavy columns might be confused with another periodic instability known in highly eroded igneous rocks, that of vesicle layering [see, e.g., Toramaru et al., 1996]. Both types of feature show band-like structure perpendicular to the joint propagation direction. However, vesicle layering is caused by differential erosion of the exposed surfaces of lava due to underlying periodic heterogeneities in crystal structure and chemical composition [Toramaru et al., 1996]. Wavy columns can be seen in cases where striae are still clearly visible, indicating that there has been little to no erosion of the column surfaces. Further, as is indicated in Figure 8a, undulations are also visible on the joints extending into the lava flow, between two adjacent columns. This type of feature could not be caused by erosion. Nor would vesicle layering lead to a wavelength which was related to the column diameter. We instead conjecture that the undulations of wavy columns are the result of an oscillatory instability of the fracture tips as they advance to form the column faces, as discussed in section 8.4.

\section{Analysis}

[40] In this section, we will analyze the data discussed above using models of the evolution of the thermal and rheological state of the flow during cooling. The important properties and their estimated values are given in Table 3. Although the CRBG has been well characterized chemically, most of its physical properties have to be estimated from other tholeiitic basalts (typically from recent Hawaiian eruptions). We measured the density $\rho$ directly from rock samples collected in the field, at room temperature. The thermal conductivity $\lambda$ has been previously measured in the Picture Gorge member of the CRBG by Murase and McBirney [1973]. The glass transition temperature $T_{g}$ was taken to be $750^{\circ} \mathrm{C}$ to be consistent with the observations of Ryan and Sammis [1981], who measured $T_{g}$ in basalt from Hawaii through a stress relaxation technique. In order to take into account the results of Peck and Minakami [1968], who observed the initiation of surface cracks, in a cooling lava lake, at $900^{\circ}$, we will also consider the implications of a higher $T_{g}$. Most of the remainder of the values in Table 3 were compiled from the sources cited by Touloukian et al.
[1989]. When the temperature dependence of a property is known, we have chosen values close to, but below, the glass transition temperature of the lava.

\subsection{Conductive Cooling Regime}

[41] Within the solid material of a colonnade, heat moves diffusively and

$$
\partial_{t} T=\kappa \nabla^{2} T,
$$

where $T$ is the temperature field. The thermal diffusivity $\kappa$ of basalts in the CRBG is not strongly dependent on temperature [Murase and McBirney, 1973]. In addition to the diffusive motion of heat, the presence of water in the cracks is known to produce convective heat transport, which will enhance the cooling under certain conditions [Hardee, 1980; Budkewitsch and Robin, 1994]. However, near the flow margins, or in cases where there is insufficient water to efficiently activate convective heat transport, cooling will be dominated by bulk diffusion. We shall therefore consider diffusive cooling first, and postpone discussion of convective effects until section 7.2.

[42] We can model the initial state of the lower part of the flow unit as a half-space $z \geq 0$, which is initially at a high temperature $T_{1}$ at time $t=0$. In order for this to be a valid model of the local heat flux, it need only be the case that the vertical coordinate of the basal cooling surface is varying slowly with respect to the average crack spacing. If this assumption was violated, the columns would not form as straight pillars, but would rather curve along with the resulting uneven temperature profile, as was described by Mallet [1875].

[43] We consider two types of boundary condition on the cooling surface. The basal surface $z=0$ could be held at a constant (cooler) temperature $T_{0}$, corresponding to a Dirichlet boundary condition on $T$. Alternatively, the basal surface could be thermally coupled to a second half-space $z<0$, initially at $T_{0}$. These two possible boundary conditions represent the limiting cases of emplacement on a wet, porous substrate where water can efficiently extract heat from the basal lava surface, or emplacement on a dry, thermally conductive substrate, respectively. We expect the near-surface cooling to develop somewhere between

Table 3. Estimated Physical Properties of Basalts From the $\mathrm{CRBG}^{\mathrm{a}}$

\begin{tabular}{|c|c|c|c|}
\hline Property & Symbol & Value & References \\
\hline Density & $\rho$ & $2850 \mathrm{~kg} \mathrm{~m}^{-3}$ & this paper \\
\hline Thermal diffusivity & $\kappa$ & $6.5 \times 10^{-7} \mathrm{~m}^{2} \mathrm{~s}^{-1}$ & $\lambda / \rho c_{p}$ \\
\hline Thermal conductivity & $\lambda$ & $1.7 \mathrm{~W}\left(\mathrm{~m}{ }^{\circ} \mathrm{C}\right)^{-1}$ & $1,2,3$ \\
\hline Poisson's ratio & $v$ & 0.2 & 2,4 \\
\hline Young's modulus & $E$ & $50 \mathrm{GPa}$ & 2,5 \\
\hline Specific heat & $c_{p}$ & $900 \mathrm{~J}\left(\mathrm{~kg}{ }^{\circ} \mathrm{C}\right)^{-1}$ & $2,3,6,7$ \\
\hline Latent heat & $L$ & $400 \mathrm{~kJ} \mathrm{~kg}^{-1}$ & 7 \\
\hline $\begin{array}{l}\text { Linear coefficient of thermal } \\
\text { expansion }\end{array}$ & $\alpha$ & $7 \times 10^{-6}{ }^{\circ} \mathrm{C}^{-1}$ & 2,8 \\
\hline Glass transition temperature & $T_{g}$ & $750^{\circ} \mathrm{C}$ & 8,9 \\
\hline Tensile strength & $\sigma_{\max }$ & $8.5 \mathrm{MPa}$ & 4,5 \\
\hline
\end{tabular}

${ }^{\mathrm{a}}$ Data are taken from 1, Murase and McBirney [1973]; 2, Touloukian et al. [1989]; 3, Petrunin et al. [2001]; 4, Peck and Minakami [1968]; 5, Bacon [1962]; 6, Mostafa et al. [2004]; 7, Hardee [1980]; 8, Ryan and Sammis [1981]; 9, Lore et al. [2000]. 
Table 4. Rates of Stria Height Increase as a Function of Distance Away From the Basal Flow Margin Taken From Figure 6 and the Estimated Temperature Differences Across the Stria Height $\Delta T$ for Two Different Boundary Conditions

\begin{tabular}{lccc}
\hline Site Description & Slope $(\langle s\rangle / z)$ & $\Delta T_{\text {Dirichlet }}$ & $\Delta T_{1 / 2 \text { space }}$ \\
\hline Rock River Road & $2.5 \pm 0.5 \%$ & $13 \pm 2{ }^{\circ} \mathrm{C}$ & $5 \pm 1{ }^{\circ} \mathrm{C}$ \\
Tucannon River & $4.5 \pm 0.6 \%$ & $23 \pm 3^{\circ} \mathrm{C}$ & $8 \pm 1^{\circ} \mathrm{C}$ \\
Clarkston & $3.2 \pm 1.3 \%$ & $16 \pm 6^{\circ} \mathrm{C}$ & $6 \pm 2^{\circ} \mathrm{C}$ \\
\hline
\end{tabular}

these two extremes. The solution to equation (2) for $t>0$, under these conditions, is

$$
U(z, t)=\operatorname{erf}\left[\frac{z}{\sqrt{4 \kappa t}}\right]
$$

where the reduced temperature $U=\left(T-T_{0}\right) /\left(T_{1}-T_{0}\right)$ for the Dirichlet conditions, or $U=\left(2 T-\left(T_{0}+T_{1}\right)\right) /\left(T_{1}-T_{0}\right)$ for the coupled half-space conditions.

[44] We assume that the stria marks are produced by cracks which propagate between an average initiation stress $\sigma_{\text {init }}$ and a termination stress $\sigma_{\text {term }}$, and that these stresses are directly related to corresponding material temperatures $T_{\text {init }}$ and $T_{\text {term }}$. Under these assumptions, we can predict that the average stria height $\langle s\rangle$ represents the distance between the two fixed isotherms $T=T_{\text {init }}$ and $T=T_{\text {term }}$. Thus, the stria heights can be used as a proxy to track the evolution of the temperature field during the cooling process. Conversely, models of the evolution of the temperature field can be used to predict features of the stria heights, at least on average [Reiter et al., 1987; DeGraff and Aydin, 1993; Grossenbacher and McDuffie, 1995].

[45] In reduced form, the average crack initiation temperature is $U_{\text {init }}=U\left(T_{\text {init }}\right)$, and the crack termination temperature is $U_{\text {term }}=U\left(T_{\text {term }}\right)$. The above assumptions imply that

$$
\langle s\rangle=\left[\frac{\operatorname{erf}^{-1}\left(U_{\text {term }}\right)}{\operatorname{erf}^{-1}\left(U_{\text {init }}\right)}-1\right] z,
$$

which predicts a linear increase in stria height with distance away from a flow margin along the normal direction $z$.

[46] Table 4 shows the results of solving equation (4) for the temperature change across a stria $\Delta T=T_{\text {init }}-T_{\text {term }}$, using the data presented in Figures $6 \mathrm{a}-6 \mathrm{c}$. Calculations for both types of boundary condition are shown. We assumed an emplacement temperature $T_{1}=1090^{\circ} \mathrm{C}$, an initial substrate temperature $T_{0}=20^{\circ} \mathrm{C}$, and a fracture initiation temperature at the glass transition temperature, $T_{\text {init }}=T_{g}$. The data presented in Table 4 suggest that the temperature difference across a stria is in the range $7-15^{\circ} \mathrm{C}$. The fracture temperature $T_{\text {init }}$ is not well constrained and may be as high as $900^{\circ} \mathrm{C}$ [Peck and Minakami, 1968]. Fortunately, the gradients in the temperature field do not strongly depend on the particular isotherm chosen as $T_{i n i t}$. In general, as $T_{\text {init }}$ increases to $900^{\circ} \mathrm{C}$, the estimates of $\Delta T$ from the two boundary conditions converge. The allowed range of $\Delta T$ for $T_{\text {init }}=900^{\circ} \mathrm{C}$ is $9-13^{\circ} \mathrm{C}$. As there are no other adjustable variables in equation (4), we can be confident that $\Delta T=11 \pm$ $4^{\circ} \mathrm{C}$.

[47] We can estimate the stress which develops in a thermally inhomogeneous layer, with no viscous relaxation, assuming that the layer is constrained horizontally but free to contract vertically (see Turcotte and Schubert [2001, section 4-22] for details of this problem). The thermal stress, $\sigma$, which builds up under these conditions, is given by

$$
\sigma=\frac{\alpha E \Delta T}{(1-\nu)}
$$

where the various properties are given in Table 3. The temperature difference $\Delta T=11 \pm 4^{\circ} \mathrm{C}$, estimated above, corresponds to a tensile strength in the presence of an existing crack tip of 3-7 MPa. This is quite reasonable considering the brittle nature of basalt, which has a measured tensile strength of $8-10 \mathrm{MPa}$ at room temperature [Peck and Minakami, 1968; Touloukian et al., 1989]. Even allowing for the uncertainty in the physical properties of basalt, and for some viscous relaxation near the solidus, it would be difficult to rectify temperature differences of more than $\sim 20^{\circ} \mathrm{C}$ with the known strength of basalt.

[48] It is interesting to calculate the heat flux through the basal surface using this model. This heat flux will later be compared with that caused by crack-aided cooling, and used to put limits on the physical processes responsible for columnar joints. $Q$, the heat flux per unit area across the plane $z=0$, can be found by integrating $1-U(z, t)$ throughout the flow, and then differentiating with respect to time, yielding

$$
Q=c_{p} \rho\left(T_{1}-T_{0}\right) \sqrt{\frac{\kappa}{\pi t}}
$$

for the case of a Dirichlet boundary condition. With the coupled half-space boundary conditions, the flux is exactly half the value given by equation (6).

[49] Thus far, the model does not take into account the release of latent heat by the solidifying basalt. Including latent heat $L$ converts the calculation into a moving boundary problem of the Stefan type, where the speed of the solidification front is limited by the rate of extraction of the latent heat. In this case, the heat flux $Q$ is given by equation (6) corrected by the factor $1 / \operatorname{erf}\left(\lambda_{1}\right)$, where $\lambda_{1}$ is given by

$$
\frac{L \sqrt{\pi}}{c_{p}\left(T_{1}-T_{0}\right)}=\frac{e^{-\lambda_{1}^{2}}}{\lambda_{1} \operatorname{erf}\left(\lambda_{1}\right)}
$$

(see Turcotte and Schubert [2001, section 4-18] for more detail). Using the thermal properties of CRBG basalt given in Table 3, $\operatorname{erf}\left(\lambda_{1}\right)=0.77$.

[50] We have now shown that in conditions where cooling is dominated by bulk diffusion, we can interpret the observed increase in stria heights with respect to vertical position, in terms of the evolution of the temperature field. As the cooling front slows down, the thermal gradient becomes less steep, and the thermal strain leading to fracture becomes spread out over a larger volume. In response, the striae increase in size. In section 7.2, we will contrast this situation with one where a convective cooling mechanism, transporting heat through the crack network, can act to stabilize the total heat flux of a cooling colonnade. 


\subsection{Convective Cooling Regime}

[51] Sufficiently far above the lower flow margin, we have observed that the sizes of striae do not depend on position within a flow, but are instead correlated with the average column side width, $w$. Furthermore, sufficiently far above the flow margin, $w$ also appears to be unchanging in these generally well-formed flows. Both of these features were universally observed in the type II/III flows of the CRBG that we studied. For these lava flows, we hypothesize that the constant size of the striae imply that the cooling rate has been stabilized by the intrusion of water into the cracks themselves. It is well-established that two-phase convection can occur in upper colonnades as the water in the cracks boils at the $100^{\circ} \mathrm{C}$ isotherm and recondenses nearer to the flow margin [Hardee, 1980; Ryan and Sammis, 1981; Budkewitsch and Robin, 1994]. This reflux of water and steam efficiently transports heat up the cracks. There is at present no direct evidence that this mode of cooling can also be active in lower colonnades. We shall argue in the following that our measurements suggest that a similar (or perhaps identical) crack-mediated cooling mechanism must also be able to operate within lower colonnades.

[52] In order to study the temperature field far from the flow margin, we can use equation (2), but shift into the reference frame moving with the solidification front. The resulting advection-diffusion equation is

$$
\partial_{t} T=\kappa \nabla^{2} T+v \partial_{Z} T
$$

where $v$ is the solidification front velocity in the upward direction, and $Z=z-v t$ is the vertical coordinate in the comoving reference frame. In this reference frame, the cracks are stationary, neglecting the intermittent part of their motion. The convective cooling must be accounted for in the boundary conditions on $T$ at the crack surfaces.

[53] The lack of variations in the stria heights in the interior of the flow suggests that we should seek a timeindependent solution to equation (8), so that the spacing of the temperature isotherms remains fixed in the moving frame. This is also consistent with borehole measurements from the Kilauea Iki lava lake [Hardee, 1980], which show that the advance of the temperature front in the upper cooling layer is well fit by a steady state solution of equation (8).

[54] In the time-independent case, we can simplify the dynamics of equation (8) by introducing the Péclet number

$$
P e=\frac{v R}{\kappa},
$$

where $R$ is a representative length scale in the problem. To simplify the geometry, it is sensible to choose $R$ to be the radius of a cylinder with the same cross-sectional area as a hexagonal column with equal sides of length $\langle w\rangle$. This implies that $R \simeq 0.91\langle w\rangle$.

[55] As before, we introduce the reduced temperature field $U=\left(T-T_{0}\right) /\left(T_{1}-T_{0}\right)$ and obtain a nondimensionalized form of the advection-diffusion equation

$$
\nabla^{\prime 2} U+P e \partial_{Z^{\prime}} U=0
$$

where $Z^{\prime}=Z / R$.
[56] The temperature near the crack tips is approximately $T_{g}$; so on the basis of the conductive solution discussed above, the $100^{\circ} \mathrm{C}$ isotherm must be several column radii removed from there. The measurements of Hardee [1980] suggest that in this intermediate zone, the cracks are filled with steam. As a first approximation to the convective cooling effect, we consider a lower colonnade model where $T=T_{0}=100^{\circ} \mathrm{C}$ below some plane $Z^{\prime}=0$. This would be the situation if the region below this plane (the convective layer) is uniformly and efficiently cooled by two-phase convection, while the region above (the conductive layer) is maintained with no net heat flux into the steam-filled cracks. The solution to equation (10) with this boundary condition is

$$
U\left(Z^{\prime}\right)=1-\exp \left(-Z^{\prime} P e\right)
$$

When this solution is inverted,

$$
Z^{\prime}=\frac{Z}{R}=-\frac{1}{P e} \log (1-U),
$$

we obtain an estimate of the Péclet number

$$
P e=\frac{R}{\langle s\rangle} \log \left[\frac{1-U_{\text {init }}}{1-U_{\text {term }}}\right]
$$

by the application of our previous assumption that $\langle s\rangle=$ $Z\left(U_{\text {term }}\right)-Z\left(U_{\text {init }}\right)$.

[57] The main uncertainty in evaluating equation (13) is the statistical fluctuation of the stria height to column width ratio $\eta$, as shown in Figure 5. Using the measured average $\eta=0.14$, and $\sigma_{\eta}=0.06$, we find $P e=0.3 \pm 0.1$. There exist examples of column geometries which have values of $P e$ throughout this range. Introducing this range of $P e$ back into equation (11) implies that the distance between the $100^{\circ} \mathrm{C}$ and $750^{\circ} \mathrm{C}$ isotherms must be $4-5$ column radii.

[58] With this model, we can make a number of estimates of the heat flux that must be carried through the cracks. This will allow us to consider the efficiency of crack-aided cooling, and to check our observations against published thermal measurements from near the upper flow surface of Kilauea Iki [Hardee, 1980].

[59] A simple order-of-magnitude heat flux estimate can be obtained by considering the data presented in Figures $6 \mathrm{~b}$ and $6 \mathrm{~d}$. These data were gathered on columns where $w$ was $50-75 \mathrm{~cm}$ and show that for these colonnades, the average stria height has ceased to increase beyond a distance of 3-4 $\mathrm{m}$ from the flow margin. Comfortingly, this agrees with the estimate just made, that the thickness of the conductive layer is approximately $4-5$ column radii. If we assume that at this distance from the margin, the crack-assisted heat flux matches the diffusive heat flux through the flow, we can use equation (3) to determine when the $T_{g}$ isotherm reaches this position. We can then use equations (6) and (7) to estimate a convective heat flux of $400 \pm 300 \mathrm{~W} \mathrm{~m}^{-2}$ for columns of this size.

[60] We can make a more rigorous estimate of heat flux by noting that for a solidification front which is steadily 
advancing at speed $v$, energy balance requires that the heat flux

$$
Q=\rho v\left(c_{p}\left(T_{1}-T_{0}\right)+L\right) .
$$

Conservation of energy implies that this is both the heat flux transmitted through the boundary layer of the conductive layer modeled by equation (11), and the heat flux carried by the cracks down through the convective layer. We can thus use equations (9) and (13) to eliminate $v$, and obtain

$$
Q=\frac{\rho \kappa}{\langle s\rangle}\left(c_{p}\left(T_{1}-T_{0}\right)+L\right) \log \left[\frac{1-U_{\text {init }}}{1-U_{\text {term }}}\right] .
$$

Using the values estimated previously, this gives $Q\langle s\rangle=$ $80 \pm 30 \mathrm{~W} \mathrm{~m}^{-1}$. In the CRBG, we observed that $\langle s\rangle$ ranges from 3.5 to $36 \mathrm{~cm}$, hence we estimate that the total heat flux through the flow surfaces can range between 200 and $2000 \mathrm{~W} \mathrm{~m}^{-2} . Q$ and $\langle s\rangle$ are inversely related, and hence so are $Q$ and $\langle w\rangle$. The smallest columns have the largest values of $Q$ and vice versa.

[61] It is insightful to consider this problem in terms of the heat flux per unit crack length. We can estimate the crack density per unit area, $\rho_{c}$, to be the ratio of half the perimeter of a hexagonal column with side length $\langle w\rangle$ to its area. The factor of one half arises because each crack is shared between two columns. Thus,

$$
\rho_{c}=\frac{\left[\frac{1}{2} \times 6\langle w\rangle\right]}{\left[(3 / 2) \sqrt{3}\langle w\rangle^{2}\right]}=\frac{2}{\sqrt{3}}\left[\frac{1}{\langle w\rangle}\right] .
$$

The heat flux per unit crack length is

$$
q_{c}=Q / \rho_{c}=\left(\frac{\sqrt{3}}{2}\right) Q\langle w\rangle=\left(\frac{\sqrt{3}}{2}\right) \frac{Q\langle s\rangle}{\eta},
$$

where we have used $\eta=\langle s\rangle /\langle w\rangle$. Thus, $q_{c}$ can be expressed as the ratio of two rather well measured quantities, $Q\langle s\rangle$ and $\eta$, which consist only of known material parameters and statistical data from many sites. Using the value of $Q\langle s\rangle$ discussed above, and $\eta=0.14 \pm 0.02$, we find $q_{c}=500 \pm$ $200 \mathrm{~W} \mathrm{~m}^{-1}$.

[62] This level of cooling could be maintained by boiling and condensing $0.2 \mathrm{~mL} \mathrm{~s}^{-1}$ of water per meter of crack cross-sectional length. This does not seem to be an unreasonable volume of water to reflux. It is interesting to note that the estimated heat flux per unit crack length does not vary by more than a factor of 2 or so between all the colonnades that we have studied.

[63] An independent estimate of heat flux through crackaided cooling can be obtained from the measurements of Hardee [1980]. He measured the depth of the solidus at the Kilauea Iki lava lake, recording a steady advance rate of $6.7 \times 10^{-8} \mathrm{~m} \mathrm{~s}^{-1}$. In this case, the heat flux given by equation (14) evaluates to $270 \mathrm{~W} \mathrm{~m}^{-2}$, using the properties that Hardee [1980] estimates for Kilauea Iki lava, or to $250 \mathrm{~W} \mathrm{~m}^{-2}$ using the properties listed in Table 3. This is consistent with our geometrically based heat flux estimates, as jointing in the vicinity of the Kilauea Iki lava lake typically has rather large columns, of 1-2 $\mathrm{m}$ in radius [Peck and Minakami, 1968]. The
$P e$ of the cooling front in the upper regions of the Kilauea Iki lava lake is thus $0.15 \pm 0.1$ [Hardee, 1980; Goehring et al., 2006], which agrees with the value we have estimated for data primarily from lower colonnades. Under these conditions, Hardee also reported that the $100^{\circ} \mathrm{C}$ and $900^{\circ}$ isotherms, measured in boreholes made into the lava lake, were consistently 7-8 m apart, from between 2 and 20 years after the initial eruption. This agrees with our estimate that the thickness of the conductive layer, which we have taken to extend to the crack tips near the $750^{\circ} \mathrm{C}$ isotherm, is $4-5$ column radii.

[64] The advective-diffusive model we have described may also be applied to columnar joints in other systems. Recent experimental work on columnar jointing has focussed on the desiccation of starch slurries, as discussed in section 3. It has been found that the formation of columnar joints in this system is due to shrinkage induced by drying, and that the transport of water can be reduced to an advectiondiffusion problem analogous to that described by equation (10) [Goehring et al., 2006]. A hydraulic Péclet number of $P e^{\prime}=0.2 \pm 0.1$ was observed to describe the scaling of columnar jointing in starch, where joints are typically between $1 \mathrm{~mm}$ and $1 \mathrm{~cm}$ across [Goehring et al., 2006].

[65] In summary, we have used our stria and column scale observations to estimate the heat flux $Q$ and the Péclet number $P e$ of the advancing front. We find values of $Q$ which are consistent with measurements made in upper colonnades, and which are attainable with reasonable groundwater reflux rates. The Péclet number we find is also consistent with what is observed in starch analog experiments.

\section{Discussion}

[66] The observations and estimates discussed above need to be interpreted carefully in order to develop a consistent understanding of the mechanism of columnar jointing. Such an understanding is required to address the general problem of the scaling of striae and column sizes, and the complete dynamics of the joint formation process.

\subsection{Striae}

[67] Our results strongly suggest that there must exist an efficient means of extracting heat through the cracks of the lower colonnade, at least in the well-ordered types of colonnades that we studied. The size of the striae near the lower flow margin was observed to increase roughly linearly with distance from the cooling boundary, which would be expected if each stria, on average, represents the distance between two fixed isotherms. Further into the lower colonnade, the striae ceased to increase in size, implying a nearly constant heat flux through the basal flow margin throughout the rest of the joint forming process. Sparse data from upper colonnades suggest the same trend exists near the upper flow margin.

[68] During the early cooling of these lava flows, thermal diffusion dominates and there is a $1 / \sqrt{t}$ slowing down of the cooling rate. This decrease in cooling rate will alter $T_{g}$ slightly, because the stress relaxation time depends exponentially on the temperature [Ryan and Sammis, 1981; Lore et al., 2000]. However, this change in $T_{g}$ will have little effect on the observed stria heights. According to equation (4), the average stria height $\langle s\rangle$ depends mostly on $\Delta T$, and does not 


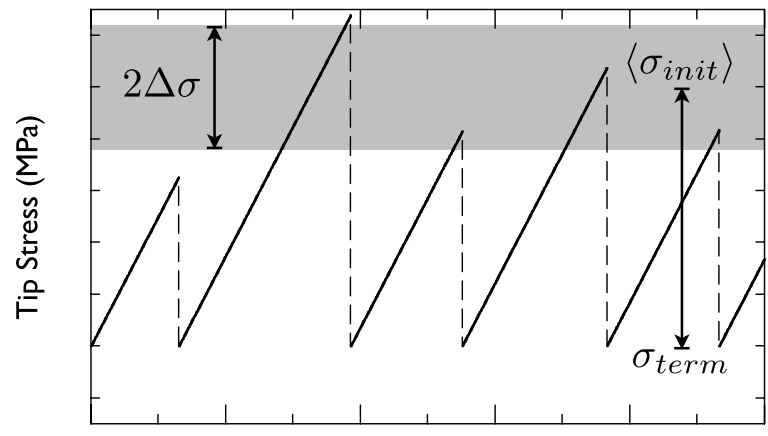

Time (arb. units)

Figure 9. Intermittent crack motion. Thermal stresses slowly build up until they are near the average crack initiation stress $\left\langle\sigma_{\text {init }}\right\rangle$. Variations in local material strength cause a spread, $\Delta \sigma$, in the individual crack initiation stress. The crack then advances rapidly until it reaches a fixed termination stress $\sigma_{\text {term }}$.

depend strongly on $T_{\text {init }}$. A decrease in $T_{\text {init }}$ from $900^{\circ} \mathrm{C}$ near the flow margin to $750^{\circ} \mathrm{C}$ within the bulk of the flow would change $\langle s\rangle$ by only $15 \%$, whereas the observed change in $\langle s\rangle$, shown in Figures $6 \mathrm{a}-6 \mathrm{c}$ is greater than $100 \%$.

[69] Similarly, the effects of the confining pressure of the lava above the growing lower colonnade cannot account for the observed growth of striae near the lower flow margin. Such pressure would not be expected to affect $\Delta T$, but could cause a slight depth dependence of $T_{\text {init }}$ by imposing a compressive pressure gradient.

[70] The vicinity of the crack tips themselves will necessarily be dry at all times, by virtue of its existing near $T_{g}$. For example, in an advective-diffusive cooling scenario with $P e=0.3$, the crack tips are 4-5 column radii away from the crack surfaces where active convective cooling is taking place. The crack surfaces in this region cannot support liquid water, due to the temperature, and the crack volume is likely filled with hot, stagnant steam [Hardee, 1980]. Thus, the fracture advance behavior of the crack tips is probably insensitive to whether the cooling is diffusive or aided by convection in the cracks. The cooling mechanism merely serves to sustain the overall heat flux $Q$.

[71] The observed independence of individual stria advances agrees with a simple mechanical model of fracture. Hot, solid basalt may be expected to have an average tensile strength of around $8-10 \mathrm{MPa}$, on the basis of measurements made at lower temperature [Touloukian et al., 1989; Peck and Minakami, 1968]. Various defects, inhomogeneities, and imperfections imply that there will be variation in the tensile strength of individual samples. For example, Bacon [1962] found samples of basalt to have an average tensile strength of $8.5 \mathrm{MPa}$, with a standard deviation of 1.6 MPa. This will translate into a spread in the thermal strains at which a crack tip will be activated. The observed $21 \%$ standard deviation in stria heights agrees well with this variation in strength. Once a crack begins to advance, it will run until it ceases to be able to release strain energy at a rate sufficient to create new crack surface [Griffith, 1921]. We can interpret this to mean that the cracks have some fixed, though not necessarily zero, termination stress. When the crack stops, it blunts, an effect which accounts for the $\sim 5 \mathrm{MPa}$ difference between the crack initiation and crack termination stresses [DeGraff and Aydin, 1993; Dufresne et al., 2006]. This type of intermittent crack motion is summarized in Figure 9 and appears to be fairly universal between various fracturing systems. It has recently been studied in detail in drying granular suspensions [Dufresne et al., 2006]. These drying suspensions form crack arrays which are reasonable two-dimensional analogs of columnar joints, and also display an incremental fracture advance similar to striae. Measurements of strain in this system show that the running crack halts at a very well defined termination stress [Dufresne et al., 2006].

\subsection{Convection}

[72] The role of water in removing heat from the interior of the flow is crucial to understanding the formation of columnar joints. It has been established [Hardee, 1980; Ryan and Sammis, 1981; Budkewitsch and Robin, 1994] that groundwater boil off and reflux is an important factor in the cooling in upper colonnades, although the exact mechanism of water transport is somewhat unclear. The observations we have made in the lower colonnades of the type II/III flows of the CRBG suggest that crack-aided cooling can also greatly influence the cooling of lower colonnades. The distinction between these flows and type I flows may, in fact, be attributable to the presence or absence of water moving within the cracks.

[73] We have argued that the constancy of the heights of the striae in the interior of lower colonnades indicates a constant average crack initiation stress, as shown in Figure 9, and a stabilization of the heat flux $Q$. Furthermore, we have argued that the heat flux per unit crack length $q_{c}$ is nearly constant in all cases. When a well-formed upper colonnade is present, it appears to have striae that are indistinguishable (other than their direction) from those in the lower colonnade, and in both cases the average stria and column sizes settle down to fixed values within a few meters of the flow margins. Also, the Péclet number calculated from our stria measurements mainly in the lower colonnades matches the value measured from borehole temperature measurements in upper colonnades [Hardee, 1980]. All these observations strongly suggest that some convective cooling mechanism operates whether the colonnade is cooling upward or downward.

[74] While it may seem intuitively clear that water is carried by gravity to the bottom of the cracks in upper colonnades, and then that buoyancy-driven convection is in the right direction to effect its transport, the reality is quite different. In fact, the narrowness of the cracks almost certainly means that capillary forces dominate over gravity. Also, the two-phase (water and steam) nature of the reflux means that the flow is more complex than what might be expected from single phase (water or steam) convection.

[75] Even if water flooded the cracks, an upper colonnade, considered as a porous medium, will have an extremely low porosity. Consequently, buoyancy-driven, D'Arcy law convection would be an extremely slow process [Bear, 1989]. Such a mechanism would not operate at all in the lower colonnade, where the buoyancy force has the wrong sign. We suggest that the direction of gravity is irrelevant to the 
cooling process, and thus that the similarity between upper and lower colonnades is less difficult to understand.

[76] The most plausible hypothesis is that the heat is transported by closed two-phase convection in unsaturated joints. Our estimates of $Q$, discussed previously, show that only a small amount of water needs be present to maintain an effective cooling cycle. As the climate of the Columbia Plateau was quite wet during the Miocene (see Long and Wood [1986] for a discussion of this), there would have been ample opportunity for sufficient groundwater to seep into the joints to account for this level of cooling. Furthermore, studies of the cooling of the upper surface of Hawaiian lava lakes show that the proposed cooling rates that we calculate are comparable to the observed cooling rates from the upper surfaces of lava lakes [Hardee, 1980; Flynn et al., 1993; Hon et al., 1994].

[77] Once water is present, capillary forces and surface adsorption will ensure that there is, at least, a film of water present on the rough, porous crack surfaces. The water film absorbs heat near the cooling front, and changes to steam. This phase change results in a pressure drop in the water phase, causing suction on the rest of the water column, drawing it toward the cooling front. In equilibrium with the water at $100^{\circ} \mathrm{C}$, the steam that is produced will not condense until it is forced to the cooler region near the flow margin. The pressures arising from the generation and condensation of steam will drive the flow of the steam phase that completes the reflux loop. This two-phase convection cycle is equivalent to the action of a heat pipe [Grover et al., 1964; Groll and Rösler, 1992]. Furthermore, Marangoni (surface tension driven) convection could also be present as a secondary effect. Surface tension gradients between the hot interior of the crack, and the cooler basal flow margin act in the right direction to assist the flow of water toward the cooling front.

[78] Unfortunately, the tortuous, fractal geometry of the cracks [Brown and Scholz, 1985; Schmittbuhl et al., 1995] complicates any simple predictions of water/steam flow rates, and hence $Q$, from heat pipe theories [Grover et al., 1964; Groll and Rösler, 1992]. Some illuminating experiments have been done on two-phase fluid flow in a single saturated crack [e.g., Brown, 1987; Auradou et al., 2001; Drazer et al., 2004], but additional experimental work will need to performed in order to make any quantitative predictions of unsaturated capillary flow through the fracture network of a cooling lava unit.

[79] While some steam might escape from upper colonnades, the large-scale horizontal uniformity of the layers of lava in the CRBG means that steam generated in the lower colonnade could not, in most cases, escape to the upper surface. It would be blocked by the melt layer between the upper and lower colonnades. However, the closed reflux of water makes the escape of steam inessential to the cooling process.

\subsection{Column Scaling}

[80] It has often been argued that the cooling rate of a lava flow determines the scale of the columnar joints that form in it [e.g., DeGraff and Aydin, 1993; Budkewitsch and Robin, 1994; Grossenbacher and McDuffie, 1995]. While there is certainly a rough proportionality between the cooling rate, as reflected in the average stria height, and the column radius, the causal relation may, in fact, be more subtle. In the presence of a crack-enhanced heat flux, the column scale, the rate of fracture advance and the rate of cooling are all interdependent.

[81] Near the flow margin of a colonnade, in both the upper and lower colonnades, there is a region of coarsening during which the column scale increases, and the columns become more ordered as they evolve toward a stable size [Peck and Minakami, 1968; DeGraff and Aydin, 1993; Lore et al., 2000]. Similar coarsening occurs in desiccated starch colonnades when the fracture front is decelerating [Goehring and Morris, 2005; Goehring et al., 2006]. In the starch case, although there is no crack-enhanced evaporation, it has been observed that the coarsening halts when the fracture front is forced to maintain a constant velocity [Goehring et al., 2006]. It is natural to suppose that the stabilization of the column size in lava occurs in a similar way, i.e., when the fracture front settles down to a fixed velocity. As mentioned in section 7.2, the scaling of the constant velocity advectiondiffusion problem, in starch, depends only on the hydraulic Péclet number [Goehring et al., 2006]. We propose also that the Péclet number $P e$ is the most important parameter controlling the scaling of the columns in lava.

[82] It is clear on physical grounds that $P e$ must not be too different from unity; a very large $P e$ would imply that the cracks move through an essentially fixed temperature field, and thus would not be dynamically affected by that field. On the other hand, a very small $P e$ would mean that temperature gradients near the crack tips would be smoothed out. Our observations on the CRBG and in starch dessication [Goehring et al., 2006] suggest that both processes happen at $P e \approx 0.3$.

[83] If the fractures advance at nearly constant $P e$, we predict that the product of the solidification front velocity $v$ and the column size $R$ should be constant. According to equation (9), $v R=\kappa P e$. We can arrive at the same conclusion by considering the mechanism for heat transport by water reflux in the cracks. According to equation (15), energy balance requires that the heat flux $Q$ is proportional to the crack advance speed $v$, with the constant of proportionality depending only on material parameters. The crack density per unit area $\rho_{c}$, given by equation (16), scales as $1 / R$. Hence the heat flux per unit crack length $q_{c}$, given by equation (17), scales as $q_{c}=Q / \rho_{c} \sim Q R \sim v R \sim P e$. Thus, the constancy of the Péclet number can be understood as equivalent to the constancy of $q_{c}$, the amount of heat that the cracks carry per unit length, per unit cross-sectional area. This is fixed by the $R$-independent, small-scale physics of an individual crack which depends only on the typical crack opening and the properties of water such as the surface tension, latent heat, etc. The inverse relationship between the cooling rate $Q$ and the column scale $R$ is thus explained.

[84] There is still some freedom in the column scale, however. The scaling of columnar joints in basalt may allow some hysteresis due to the inherent rigidity of the column pattern, which typically changes scale only by the mechanism of crack stopping. There is good evidence for such hysteresis in starch colonnades [Toramaru and Matsumoto, 2004; Goehring and Morris, 2005; Goehring et al., 2006] and in 2-D desiccation analogs of columnar joints [Shorlin et al., 2000; Deegan et al., 2003]. This effect, although difficult to observe directly through field observations, 
probably means that there exists a finite range of stable scales near $P e \approx 0.3$.

\subsection{Wavy Columns}

[85] In a small number of CRBG sites, we have observed that the column diameters oscillate, or undulate, as a function of the column's height. We can say little conclusive about such wavy columns other than that they exist, although not in most colonnades, and that their period and amplitude appear to scale linearly with column diameter. Their wavelength is sufficiently large that they cannot be explained by a radial alternation of individual stria advances, even in cases where striae themselves cannot be observed because of weathering.

[86] Wavy columns bear a striking resemblance to sinusoidal cracks that appear in thin, thermally stressed strips. Yuse and Sano [1993] showed that a slowly advancing crack tip intruding into a cooling glass strip can advance in an oscillatory manner. Ronsin and Perrin [1987] studied the transition between straight and wavy cracks in a periodic array, and showed that an oscillatory instability develops when cracks get too far apart from each other. Although these experiments were in 2-D analog systems, it seems entirely plausible that a similar instability could generate wavy columns in 3-D columnar joints. Wavy columns have not yet been observed in 3-D laboratory analogs, however.

\subsection{Residual Disorder}

[87] Even mature arrays of columns exhibit significant disorder, which is not eliminated by further evolution of the crack network. We have observed that the standard deviation of the distribution of side lengths is the same, within statistical error, for all of 20 different sites. These sites included both upper and lower colonnades. This statistic agrees quantitatively with the corresponding measure of disorder in starch colonnades [Goehring and Morris, 2005], and with the survey of O'Reilly [1879]. The standard deviation of the joint angle distribution also agrees, within error, with measurements of starch and O'Reilly [1879]. The crack network does not evolve toward perfect hexagonal symmetry, but rather to an unsteady pattern whose statistics deviate from perfection by an amount which is similar in all mature patterns, regardless of their scale or host medium.

[88] Aydin and DeGraff [1988] showed that the incremental growth of striae can allow sequential striae to be slightly misaligned, giving rise to a fracture network that can change as it advances. They proposed that this adjustment mechanism explains why the surface of a lava flow shows rectilinear cracks, while the interior shows hexagonal cracks. This ordering evolution is evident both in columnar joints and their laboratory analogs. But this mechanism also works equally well to explain the continued evolution of the fracture network, even after it has reached a roughly hexagonal state. This continued evolution acts to maintain a residual level of disorder. In analog experiments, 3-D X-ray tomography of starch colonnades allows one to directly observe that the cracks continue to move around as they penetrate into the bulk of the sample, even when the evaporation rate is controlled [Goehring et al., 2006]. The presence of the oscillatory instability, first reported here, shows that igneous columnar jointing can also have coherent, and not merely random, joint motion in the mature state.

\subsection{Model Extensions}

[89] We have developed a model of cooling and cracking that results in well-formed, regular colonnades. We have assumed the simplest case of a thick, planar flow, and argued that water reflux is responsible for the constancy of the fracture advance rate, and hence column size, in these flows. This model explains our observations of the evolution of stria heights and column face widths. The flows in the CRBG have sometimes been classified into three types. Our results most directly apply to thick type II/III flows, especially to lower colonnades where the average column side width is between 25 and $100 \mathrm{~cm}$.

[90] To extend our model to more general cases, we must consider how relaxing our simplifying assumptions is likely to change its predictions. In many flows, for example, the cooling front is not planar. Mallet [1875] showed how flows that are confined by microrelief give rise to curved or tapering colonnades. Similarly, DeGraff and Aydin [1987] observed cases where fans of columns radiate from large 'master cracks', which they suggested act as cooling centers. In these situations, the speed of the fracture front and size of the column diameters will be strongly influenced by geometric effects, as well as on whether or not water is present in the cracks. However, we conjecture that a local Péclet number near 0.3 will continue to govern the crack spacing and hence the scale of the joints, to within some hysteretic window [Goehring et al., 2006] if this scale is rapidly changing in space.

[91] Type I flows are thinner (10-30 m thick) than the type II/III flows we have studied here, and have larger columns in irregular, tapering colonnades [Long and Wood, 1986]. These morphologies suggest that they formed solely through conductive cooling. In some cases, it has been convincingly argued that certain flows were emplaced over partially solidified lobes of the same eruption [Thordarson and Self, 1998]. These would necessarily be dry substrates, and would produce more complex cooling patterns than we have considered. A detailed analysis of the heights of striae throughout such a flow could be particularly useful for inferring the cooling history of these flows.

[92] For extremely thin flows, which would include most flows less than $10 \mathrm{~m}$ thick, there is insufficient space for crack-aided cooling to develop as an efficient means of extracting heat. In these cases, as in the study of Lore et al. [2000], one would need to consider the added complication of the simultaneous heat loss through both the nearby flow boundaries. A model of this type could be applied to intrusive features, such as dikes and sills (S. Shoreland-Ball et al., Columnar jointed tuffs below a doleritic sill, Tideswell Dale, Derbyshire, submitted to Journal of the Geological Society, 2008). Even in these cases, we would still expect a general relationship between column size, stria height, and heat flux to continue to hold locally.

\section{Conclusion}

[93] We have presented observations and detailed analysis of columnar jointing in the Columbia River Basalt Group. We have emphasized quantitative measurements of the various length scales observable on the columns, including the striae on the column faces and their positions relative to the flow margin. Our analysis gives a consistent physical 
description of the fracture processes in cooling lava flows, and makes clear their connection to laboratory analog systems. We examined the statistics of the individual fracture advances recorded in the striae. Thermal modeling was used to deduce that the same convective cooling mechanism known from upper colonnades can also operate in lower colonnades. The details of the thermal models allowed us to identify the Péclet number as the important quantity controlling the size of the columns, possibly within some hysteretic window. This analysis also made quantitative the relationship between the cooling rate and the scale of the columns. We presented observations of a new dynamical state of the evolving column pattern, an oscillatory mode that results in wavy columns.

[94] Although the goals of this paper has been to present and interpret field observations confined to one very homogenous system, the Columbia River Basalt Group, we believe that the conclusions we report will be generally applicable to all igneous columnar joints. Most igneous systems that support columnar jointing are relatively similar, and differences in physical properties can be taken into account by a suitable scaling, or reinterpretation, of our results.

[95] Acknowledgments. We thank Catherine Duquette and Brian Goehring for their assistance in the field and Mark Jellinek, Sandy Cruden, and Pierre-Yves Robin for their advice in organizing our expedition; and we further thank Pierre-Yves Robin for advice when preparing this manuscript. Funding for the field component of this research was supplied by the Rita Catherall Bursary Fund.

\section{References}

Allain, C., and L. Limat (1995), Regular patterns of cracks formed by directional drying of a colloidal suspension, Phys. Rev. Lett., 74(15), $2981-2984$.

Auradou, H., J.-P. Hulin, and S. Roux (2001), Experimental study of miscible displacement fronts in rough self-affine fractures, Phys. Rev. E, 63 , 066306.

Aydin, A., and J. M. DeGraff (1988), Evolution of polygonal fracture patterns in lava flows, Science, 239, 471-476.

Bacon, L. O. (1962), A method of determining dynamic tensile strength of rock at minimum loading, U. S. Dep. Mines Rep. Invest., 6067, 22 pp.

Bear, J. (1989), Dynamics of Fluids in Porous Media, 784 pp., Dover, Mineola, N. Y.

Bretz, J. H., H. T. U. Smith, and G. E. Neff (1956), Channeled scabland of Washington: New data and interpretations, Geol. Soc. Am. Bull., 67, 957-1049.

Brown, S. R. (1987), Fluid flow through rock joints: The effect of surface roughness, J. Geophys. Res., 92, 1337-1347.

Brown, S. R., and C. H. Scholz (1985), Broad bandwidth study of the topography of natural rock surfaces, J. Geophys. Res., 90, 12,57512,582 .

Budkewitsch, P., and P.-Y. Robin (1994), Modelling the evolution of columnar joints, J. Volcanol. Geotherm. Res., 59, 219-239.

Bulkeley, R. (1693), Part of a letter from Sir R.B.S.R.S. to Dr. Lister, concerning the giants causway in the county of Atrim in Ireland, Philos. Trans. R. Soc. London, 17, 708-710.

Coffin, M. F., and O. Eldholm (1994), Large igneous provinces: Crustal structure, dimensions, and external consequences, Rev. Geophys., 31, 136.

Deegan, R. D., S. Chheda, L. Patel, M. Marder, H. L. Swinney, J. Kim, and A. de Lozanne (2003), Wavy and rough cracks in silicon, Phys. Rev. E, 67, 066,209.

DeGraff, J. M., and A. Aydin (1987), Surface morphology of columnar joints and its significance to mechanics and direction of joint growth, Geol. Soc. Am., 99, 605-617.

DeGraff, J. M., and A. Aydin (1993), Effect of thermal regime on growth increment and spacing of contraction joints in basaltic lava, J. Geophys. Res., 98, 6411-6430.

DeGraff, J. M., P. E. Long, and A. Aydin (1989), Use of joint-growth directions and rock textures to infer thermal regimes during solidification of basaltic lava flows, J. Volcanol. Geotherm. Res., 38, 309-324.
Drazer, G., H. Auradou, J. Koplik, and J. P. Hulin (2004), Self-affine fronts in self-affine fractures: large and small-scale structure, Phys. Rev. Lett., 92, 014501.

Dufresne, E. R., et al. (2003), Flow and fracture in drying nanoparticle suspensions, Phys. Rev. Lett., 91, 224501.

Dufresne, E. R., D. J. Stark, N. A. Greenblatt, J. X. Cheng, J. W. Hutchinson, L. Mahadevan, and D. A. Weitz (2006), Dynamics of fracture in drying suspensions, Langmuir, 22, 7144-7147.

Flynn, L. P., P. J. Mouginismark, J. C. Gracie, and P. G. Lucey (1993), Radiative temperature-measurements at Kupaianaha lava lake, Kilauea volcano, Hawaii, J. Geophys. Res., 98, 6461-6476.

French, J. W. (1925), The fracture of homogeneous media, Trans. Geol. Soc. Glasgow, 17, 50-68.

Goehring, L., and S. W. Morris (2005), Order and disorder in columnar joints, Europhys. Lett., 69, 739-745.

Goehring, L., Z. Lin, and S. W. Morris (2006), An experimental investigation of the scaling of columnar joints, Phys. Rev. E, 74, 036,115.

Griffith, A. A. (1921), The phenomena of rupture and flow in solids, Philos. Trans. R. Soc. London, Ser. A, 221, 163-198.

Groll, M., and S. Rösler (1992), Operation principles and performance of heat pipes and closed two-phase thermosyphons, J. Non Equilib. Thermodyn., 17, 91-151.

Grossenbacher, K. A., and S. M. McDuffie (1995), Conductive cooling of lava: Columnar joint diameter and stria width as functions of cooling rate and thermal gradient, J. Volcanol. Geotherm. Res., 69, 95-103.

Grover, G. M., T. P. Cotter, and G. F. Erickson (1964), Structures of very high thermal conductance, J. Appl. Phys., 35, 1990-1991.

Hardee, H. C. (1980), Solidification in Kilauea Iki lava lake, J. Volcanol. Geotherm. Res., 7, 211-223.

Ho, A. M., and K. V. Cashman (1997), Temperature constrains on the ginko flow of the Columbia River Basalt Group, Geology, 25, 403-406.

Hon, K., J. Kauahikaua, R. Denlinger, and K. Mackay (1994), Emplacement and inflation of pahoehoe sheet flows: Observations and measurements of active lava flows on Kilauea volcano, Hawaii, Geol. Soc. Am. Bull., 106, 351-370.

Hooper, P. R., and C. J. Kawkesworth (1993), Isotopic and geochemical constraints on the origin and evolution of the Columbia River basalt, J. Petrol., 34, 1203-1246.

Huxley, T. H. (1881), Physiography: An Introduction to the Study of Nature, 204 pp., MacMillan, London.

Jagla, E. A., and A. G. Rojo (2002), Sequential fragmentation: The origin of columnar quasihexagonal patterns, Phys. Rev. E, 65, 026203.

Long, P. E., and B. J. Wood (1986), Structures, textures and cooling histories of Columbia River basalt flows, Geol. Soc. Am. Bull., 97, 1144 1155 .

Lore, J., H. Gao, and A. Aydin (2000), Viscoelastic thermal stress in cooling basalt flows, J. Geophys. Res., 105, 23,695-23,709.

Mallet, R. (1875), On the origin and mechanism of production of the prismatic (or columnar) structure of basalt, Philos. Mag., 50, 122-135, $201-$ 226

Menger, F. M., H. Zhang, K. L. Caran, V. A. Seredyuk, and R. P. Apkarian (2002), Gemini-induced columnar jointing in vitreous ice: Cryo-HRSEM as a tool for discovering new colloidal morphologies, J. Am. Chem. Soc., 124, 1140-1141.

Mizuguchi, T., A. Nishimoto, S. Kitsunezaki, Y. Yamazaki, and I. Aoki (2005), Directional crack propagation of granular water systems, Phys. Rev. E, 71, 056122 .

Mostafa, M. S., N. Afify, A. Gaber, and E. F. A. Zaid (2004), Investigation of thermal properties of some basalt samples in Egypt, J. Therm. Anal. Calorimetry, 75, 179-188.

Müller, G. (1998a), Starch columns: Analog model for basalt columns, J. Geophys. Res., 103, 15,239-15,253

Müller, G. (1998b), Experimental simulation of basalt columns, J. Volcanol. Geotherm. Res., 86, 93-96.

Müller, G. (2001), Experimental simulation of joint joint morphology, J. Struct. Geol., 23, 45-49.

Murase, T., and A. R. McBirney (1973), Properties of some common igneous rocks and their melts at high temperatures, Geol. Soc. Am. Bull., $84,3563-3592$

O'Reilly, J. P. (1879), Explanatory notes and discussion on the nature of the prismatic forms of a group of columnar basalts, Giant's Causeway, Trans. $R$. Irish Acad, 26, 641-728.

Peck, D. L., and T. Minakami (1968), The formation of columnar joints in the upper part of Kilauean lava lakes, Hawaii, Geol. Soc. Am. Bull., 79 $1151-1168$

Petrunin, G. I., V. G. Popov, and V. M. Ladygin (2001), Thermal properties of basalts from the bouvet triple junction and their implications for petrophysical characteristics, Izv. Phys. Solid Earth, 37, 441-451.

Reidel, S. P., T. L. Tolan, P. R. Hooper, M. H. Beeson, K. R. Fecht, R. D. Bentley, and J. L. Anderson, (1989) The Grande Ronde basalt, Columbia 
River Basalt Group: Stratigraphic descriptions and correlations in Washington, Oregon, and Idaho, in Volcanism and Tectonism in the Columbia River Flood-Basalt Province, edited by S. P. Reidel and P. R. Hooper, Spec. Pap. Geol. Soc. Am., 239, 21-53.

Reiter, M., M. W. Barroll, J. Minier, and G. Clarkson (1987), Thermomechanical model for incremental fracturing in cooling lava flows, Tectonophysics, 142, 241-260.

Ronsin, O., and B. Perrin (1987), Thermo-mechanical model for incremental fracturing in cooling lava flows, Tectonophysics, 142, 241-260.

Ryan, M. P., and C. G. Sammis (1978), Cyclic fracture mechanisms in cooling basalt, Geol. Soc. Am. Bull., 89, 1295-1308.

Ryan, M. P., and C. G. Sammis (1981), The glass transition in basalt, J. Geophys. Res., 86, 9519-9535.

Saliba, R., and E. A. Jagla (2003), Analysis of columnar joint patterns from three-dimensional stress modeling, J. Geophys. Res., 108(B10), 2476 doi:10.1029/2003JB002513.

Schmittbuhl, J., F. Schmitt, and C. Scholz (1995), Scaling invariance of crack surfaces, J. Geophys. Res., 100, 5953-5973.

Shaw, H. R., and D. A. Swanson (1970), Eruption and Flow Rates of Flood Basalts, pp. 271-299, East. Wash. State Coll. Press, Cheney.

Shorlin, K. A., J. R. de Bruyn, M. Graham, and S. W. Morris (2000) Development and geometry of isotropic and directional shrinkage crack patterns, Phys. Rev. E, 61, 6950.

Thordarson, T., and S. Self (1998), The Roza Member, Columbia River Basalt Group: A gigantic pahoehoe lava flow field formed by endogenous processes?, J. Geophys. Res., 103(B11), 27,411-27,445.

Tolan, T. L., S. P. Reidel, M. H. Beeson, J. L. Anderson, K. R. Fecht, and D. A. Swanson (1989), Revisions to the estimates of the areal extent and volume of the Columbia River Basalt Group, in Volcanism and
Tectonism in the Columbia River Flood-Basalt Province, edited by S. P. Reidel and P. R. Hooper, Spec. Pap. Geol. Soc. Am., 239, 1-20.

Tomkeieff, S. I. (1940), The basalt lavas of the Giant's Causeway district of Northern Ireland, Bull. Volcanol., 6, 89-146.

Toramaru, A., and T. Matsumoto (2004), Columnar joint morphology and cooling rate: A starch-water mixture experiment, J. Geophys. Res., 109, B02205, doi:10.1029/2003JB002686.

Toramaru, A., A. Ishiwatari, M. Matsuzawa, N. Nakamura, and S. Arai (1996), Vesicle layering in solidified intrusive magma bodies: A newly recognized type of igneous structure, Bull. Volcanol., 58, 393-400.

Touloukian, S. Y., W. R. Judd, and R. F. Roy (1989), Physical Properties of Rocks and Minerals, 548 pp., Hemisphere, New York.

Turcotte, D. L., and G. Schubert (2001), Geodynamics, 2nd ed., 528 pp., Cambridge Univ. Press, New York.

Waitt, R. B. (1985), Case for periodic colossal jöulhlaups from Pleistocene glacial lake Missoula, Geol. Soc. Am. Bull., 96, 1271-1286.

Weibull, W. (1951), A statistical distribution function of wide applicability, J. App. Mech., 18, 293-297.

Yuse, A., and M. Sano (1993), Transition between crack patterns in quenched glass plates, Nature, 362, 329-331, doi:10.1038/362329a0.

L. Goehring, BP Institute for Multiphase Flow, University of Cambridge, Madingley Road, Cambridge CB3 0EZ, UK. (1g352@cam.ac.uk)

S. W. Morris, Department of Physics, University of Toronto, $60 \mathrm{St}$ George Street, Toronto, ON M5S 1A7, Canada. (smorris@physics. utoronto.ca) 